\title{
Cross-Sensory Correspondences and Symbolism in Spoken and Written Language
}

\author{
Peter Walker
}

Department of Psychology, Lancaster University, UK

$\&$

Department of Psychology, Sunway University, Malaysia

Word count (excluding title, references, author affiliations, acknowledgements, figures and

figure legends) $=18832$

Author Note

Correspondence to:

Peter Walker

Department of Psychology

Lancaster University

Lancaster, LA1 4YF

UK

email: p.walker@lancaster.ac.uk 


\begin{abstract}
Lexical sound symbolism in language appears to exploit the feature associations embedded in cross-sensory correspondences. For example, words incorporating relatively high acoustic frequencies (i.e., front/close rather than back/open vowels) are deemed more appropriate as names for concepts associated with brightness, lightness in weight, sharpness, smallness, speed and thinness, because higher pitched sounds appear to have these crosssensory features. Correspondences also support prosodic sound symbolism. For example, speakers might raise the fundamental frequency of their voice to emphasise the smallness of the concept they are naming. The conceptual nature of correspondences and their functional bi-directionality indicate they should also support other types of symbolism, including a visual equivalent of prosodic sound symbolism. For example, the correspondence between auditory pitch and visual thinness predicts that a typeface with relatively thin letter strokes will reinforce a word's reference to a relatively high pitch sound (e.g., squeal). An initial rating study confirms that the thinness-thickness of a typeface's letter strokes accesses the same cross-sensory correspondences observed elsewhere. A series of speeded word classification experiments then confirms that the thinness-thickness of letter strokes can facilitate a reader's comprehension of the pitch of a sound named by a word (thinner letter strokes being appropriate for higher pitch sounds), as can the brightness of the text (e.g., white-on-grey text being appropriate for the names of higher pitch sounds). It is proposed that the elementary visual features of text are represented in the same conceptual system as word meaning, allowing cross-sensory correspondences to support visual symbolism in language.
\end{abstract}

Keywords: cross-sensory correspondences, symbolism in language, typographic factors in reading, congruity effects, speeded classification 


\section{CORRESPONDENCES AND SYMBOLISM}

Cross-Sensory Correspondences and Symbolism in Spoken and Written Language

\section{Cross-Sensory Correspondences and Sound Symbolism}

Much of language embraces arbitrariness in the mappings between word forms and word meanings. For a minority of words, however, such mappings appear to be systematically appropriate (for reviews and evidence see Monaghan, Shillcock, Christiansen \& Kirby, 2012; Perniss, Thompson, \& Vigliocco, 2010). Onomatopoeia, expressives (Gasser, Sethuraman, \& Hockema, 2005), and phonaesthemes (Bergen, 2004) provide relatively transparent examples of non-arbitrary sound-meaning mappings (i.e., sound symbolism). Other examples of sound symbolism are a little less transparent. For example, new words are deemed to be more appropriate as names for visual objects when the number of syllables they incorporate (as a proxy for their complexity as a sound) is comparable with the visual complexity of the objects they name (e.g., the number of edges in their shapes) (Kelly, Springer, \& Keil, 1990). Similarly, the abruptness of the changes in intensity within a word's sound (i.e., the sharpness of its amplitude envelope, see Rhodes, 1994) can make it seem appropriate as the name for a visual object with a similar degree of abruptness (i.e., sharpness) in the changing direction of its contour (e.g., Monaghan, Mattock, and P. Walker, 2012; Nielsen \& Rendall, 2011; Westbury, 2005).

In other cases of sound symbolism it is the cross-sensory features of a word's sound (i.e., those features not normally registered through hearing, such as size, brightness and sharpness, see below) that make the word appropriate for its meaning. Sapir (1929) and Newman (1933) provide early accounts of this form of sound symbolism, pointing out that words incorporating vowel sounds with higher formant frequencies (i.e., front/closed vowels, such as in mil) seem appropriate as names for relatively small things, whereas words 


\section{CORRESPONDENCES AND SYMBOLISM}

incorporating vowel sounds with lower formant frequencies (i.e., back/open vowels, such as in $\mathrm{mal}$ ) seem appropriate as names for relatively big things. ${ }^{1}$

People might become sensitive to such an association between auditory frequency and size as a result of experiencing the natural co-occurrence of these features: In general, smaller objects resonate on impact with higher acoustic frequencies than do larger objects (see Grassi, 2005; Houben, Kohlrausch, \& Hermes, 2004; Perrott, Musicant, \& Schwethelm, 1980), and smaller animals and people tend to make vocalisations containing higher acoustic frequencies than their bigger counterparts (see, for example, Bee, Perrill, \& Owen, 2000; Davies \& Halliday, 1978; Evans, Neave, \& Wakelin, 2006; Harrington, 1987; Morton, 1994; Ohala, 1994; Pisanski, et al., 2014; Rendell, Vokey, \& Nemeth, 2007). People might also be sensitive to an aspect of size that is embedded in the mechanics of vocalisation, an aspect that helps to determine the acoustic frequencies within speech sounds. For example, to produce vowel sounds with higher formant frequencies, the tongue has to be positioned such that the oral cavity is relatively small (i.e., front/close), whereas to produce vowel sounds with lower formant frequencies, the tongue has to be positioned such that the oral cavity is relatively large (i.e., back/open). This provides another potential basis for people associating higher acoustic frequencies with smallness.

It is also possible, however, that the association between acoustic frequency (loosely, pitch) and size is a more directly perceptual one. Specifically, sounds themselves, whether speech sounds or non-speech sounds, are perceived to vary in size according to their acoustic

\footnotetext{
${ }^{1}$ Because a sound's formant frequencies vary independently of its fundamental frequency, the height of these frequencies is closely associated with the extent of their separation from the fundamental frequency, that is, their dispersion. Thus, formants with higher overall frequencies are also more dispersed. Some qualities of complex sounds (e.g., their timbre) are often referred to their formant dispersion, rather than to their frequencies per se.
} 


\section{CORRESPONDENCES AND SYMBOLISM}

frequencies. Thus, when people are asked to indicate the properties simple sounds (e.g., pure tones) are perceived to possess, sounds with relatively high acoustic frequencies are said to be smaller than those with lower acoustic frequencies (e.g., Tarte, 1982; P. Walker \& Smith, 1984). Perhaps it is this direct, and likely unlearned, perceptual association between pitch and size that recommends mil as the name for a smaller table, and mal as the name for a larger table. If it is, then an important implication follows: Additional variants of this type of sound symbolism should arise because sounds contrasting in their auditory frequencies are perceived to differ in a range of other cross-sensory features, each of which could support sound symbolism.

\section{Cross-sensory features linked to auditory pitch.}

Asked to indicate the perceived qualities possessed by simple non-speech sounds, people indicate that higher pitched sounds are not only smaller than lower pitch sounds, but also brighter, faster, higher in space, lighter in weight, sharper, and thinner (Collier \& Hubbard, 2001; Eitan \& Timmers, 2010; Hubbard, 1996; Marks, 1974, 1975, 1978; Mondloch \& Maurer, 2004; Perrott, Musicant, \& Schwethelm, 1980; Tarte, 1982; P. Walker \& Smith, 1984; L. Walker, P. Walker, \& Francis, 2012). And when they draw music they are listening to, people draw lines and forms that are more angular, brighter, higher on the page, smaller, and thinner, the higher in pitch is the music (Karwoski, Odbert, \& Osgood, 1942; Kussner \& Leech-Wilkinson, 2013). Indeed, when visual percepts are induced by nonspeech sounds in auditory-visual synaesthesia, higher pitch sounds again induce images that are brighter, higher in their spatial elevation, lighter in weight, more likely to be moving, sharper, and smaller (e.g., Chiou, Stelter \& Rich, 2013; Karwoski \& Odbert, 1938; Marks, 1974, 1975, 1978; Ward, Huckstep \& Tsakanikos, 2006).

The cross-sensory features associated with pitch lie on dimensions, with the values for 


\section{CORRESPONDENCES AND SYMBOLISM}

associated features changing systematically with each other (e.g., higher pitch suggests smaller size across all values of pitch). It appears, therefore, that it is the alignment of different feature dimensions that determines individual cross-sensory feature associations, hence the reference to two features being in correspondence with each other.

If speech sounds contrasting in their acoustic frequencies enjoy the same crosssensory correspondences as non-speech sounds, then the case for additional variants of sound symbolism is enhanced. Strong indication that they do comes from Marks' (1975) observation that the same correspondences are observed when words contrasting in the acoustic frequencies of their vowel sounds induce visual percepts in auditory-visual synaesthesia (e.g., these visual percepts are brighter, pointier, and smaller for vowel sounds having higher formant frequencies). Similarly, when people indicate the cross-sensory features possessed by vowel sounds contrasting in their formant frequencies (i.e., front/closed vowels versus open/back vowels), vowel sounds with higher formant frequencies are deemed to be brighter, faster, lighter in weight, sharper, smaller, and thinner than vowel sounds with lower formant frequencies (Becker \& Fisher, 1988; Johnson, 1967; Tarte, 1982).

\section{Cross-sensory correspondences and lexical sound symbolism.}

There is already evidence that these correspondences support additional variants of sound symbolism. Novel words incorporating vowel sounds with higher formant frequencies are judged to be more appropriate as names for things that are brighter, faster, lighter in weight, sharper, smaller, and thinner, than those incorporating sounds with lower formant frequencies (Klink, 2000; 2003; Klink \& Wu, 2014; Kohler 1947; Lowry \& Shrum, 2007; Newman, 1933; Sapir 1929; Spector \& Maurer, 2013). Furthermore, Monaghan, Mattock, and P. Walker (2012), and Jones, Vinson, Clostre, Zhu, Santiago, and Vigliocco (2014) demonstrate that symbolism based on the cross-sensory correspondence between auditory 


\section{CORRESPONDENCES AND SYMBOLISM}

pitch and visual pointiness can help a new word to become established in a language. They show how people find it easier to learn novel names for novel shapes when the acoustic frequencies in their vowel sounds are congruent with the pointy or curved nature of the shapes (higher frequencies for pointier shapes). Jones et al. (2014) also show how this particular form of sound symbolism biases the errors that occur during name learning in a way that transforms what are initially non-symbolic (arbitrary) sound-form mappings, into symbolic mappings.

The line of argument being developed here is completed with evidence that these same cross-sensory correspondences support sound symbolism in established languages. For example, when Berlin (1994) examined the complete set of names of birds and fish in the Huambisa language (an Indian language from the Peruvian rainforest), he observed more vowel sounds with higher acoustic frequencies in the names of smaller exemplars from each category than in the names of bigger exemplars. He also observed a greater prevalence of speech sounds with higher acoustic frequencies (possibly alongside sharper amplitude envelopes) in the Huambisa names for birds compared to fish, which he considered likely to symbolize the contrast in the sharpness and speed of their typical movement: Higher auditory frequencies corresponding with sharper and faster movement.

Another example is provided by McMurray (1960), who asked English language speakers to guess the meanings of each member of several antonym pairs taken from languages with which they were unfamiliar (Chinese, Czech, Hindi). He observed that they were able to do so, on the basis of the sounds of the words, at levels significantly above chance. His participants tended, for example, to judge the pair of Hindi words for brightdark themselves to differ in brightness, and also to differ in sharpness, size, speed, and weight, with brighter corresponding with sharper, smaller, faster, and lighter in weight (e.g., 


\section{CORRESPONDENCES AND SYMBOLISM}

the Hindi word for bright was judged to be faster than the Hindi word for dark). Factor analysis of participants' feature judgements across all words confirmed that when a member of an antonym pair was judged to be high (regardless of the word's actual meaning), it tended also to be judged as active, bright, fast, light, and sharp (conversely for those judged to be low).

In conclusion, cross-sensory correspondences involving the perceptual features of speech sounds appear to support varying instances of sound symbolism in language. Systematic sound-meaning mappings based on the correspondences seem to help ensure the ‘fittingness’ of a word for its meaning (e.g., McMurray, 1958).

\section{Cross-sensory correspondences and prosodic sound symbolism.}

Discussion so far has concerned how the appropriateness of a word's sound for its meaning might help to establish the word in its language, thereby introducing an element of non-arbitrariness to sound-meaning mappings. This is referred to here as lexical sound symbolism. As Marks (1978) has already noted, however, there is another type of sound symbolism involving the alternative ways in which people are able to say the same word, thereby changing how the word sounds on different occasions. This is commonly achieved through prosody, and so this type of sound symbolism is referred to here as prosodic sound symbolism.

The possibility that prosodic sound symbolism, like lexical sound symbolism, exploits the language user's sensitivity to cross-sensory correspondences has yet to be properly evaluated, but there are indications that it can and does. When they find themselves in competitive situations, several species lower the fundamental frequency of their vocalisations to give the impression they are bigger (and stronger) than they otherwise would appear (Fitch, 1999; Fitch, \& Hauser, 2002; Morton, 1994; Ohala, 1994). At the same time, they find ways 


\section{CORRESPONDENCES AND SYMBOLISM}

to look bigger (e.g., pilo-erection). People also have been observed to vary their speech in ways consistent with Ohala's (1994) frequency coding hypothesis, with the correspondence between auditory frequency and size again being used to convey power. Thus, people change their speech register during social interactions to reflect the actual, or desired, power relation they have with the person to whom they are talking. Sicoli (2010) explores how speaking in a higher pitch register is used to signal acknowledgement of the greater power (authority) of the addressee, while speaking in a lower pitch register is used to signal that the speaker has greater power. Even in non-competitive situations (e.g., when listening to a speaker read lists of words) people are sensitive to the fundamental frequency of speech when judging the size and strength (aggressiveness/masculinity) of the speaker (see, Pisanski et al., 2014; Pisanski \& Rendall, 2011).

There are now experimental demonstrations of people altering the pitch of their nonspeech vocalisations in line with some of the other cross-sensory correspondences referred to earlier. For example, when asked to reproduce a note sung by someone else, people will raise the pitch of their vocalisations if they see a task irrelevant line that is relatively thin, rather than relatively thick, appear on a computer screen they are looking at as they sing (Dolscheid, Shayan, Majid \& Casasanto, 2013). And with regard to the production of speech, when Parise and Pavani (2011) asked participants to vocalise a simple vowel (the syllable 'ah') immediately after an elementary geometric shape appeared on a computer screen, they automatically raised the pitch of their vocalisation whenever the shape was relatively pointy.

In light of recent evidence that infants appreciate at least five cross-sensory correspondences involving auditory pitch (Dolscheid, Hunnius, Casasanto, \& Majid, 2014; Haryu \& Kajikawa, 2012; Ozturk, Krehm, \& Vouloumanos, 2013; Pena, Mehler, \& Nespor, 2011; P. Walker et al., 2010), infant-directed speech promises to be a rich source of prosodic 


\section{CORRESPONDENCES AND SYMBOLISM}

sound symbolism, and evidence for this is found in Nygaard et al. (2009). Nygaard and colleagues presented adults with pictures depicting two objects contrasting in the value of a single feature and asked them to adopt a specified novel name for one of them. At the same time, the adults had to imagine they were trying to direct a young infant's attention to the chosen object using speech alone (e.g., 'Can you get the blicket one?'). One pair of objects contrasted in size, and it was arranged that on some occasions a particular nonword would name the smaller object, whereas on other occasions it would name the larger object.

Nygaard et al. discovered that nonwords were spoken with higher pitch, lower loudness, and shorter duration (faster) when they named the relatively small object. They observed that the sentence frame in which the novel name was embedded also was spoken in ways reflecting the relative size of the object being talked about (i.e., it too was spoken with higher pitch, lower loudness, and shorter duration when referring to the smaller object). Finally, Nygaard et al. went on to show how adult listeners were later able to judge to which of two contrasting objects samples of this infant-directed speech were referring, thereby confirming a role for prosodic sound symbolism in the encoding of speech, as well as its production. Though Nygaard et al. do not consider the possible involvement of cross-sensory correspondences in prosody, it is clear that correspondences are well placed to support the type of sound symbolism they observed in infant-directed speech.

Finally, the availability of prosodic sound symbolism based on cross-sensory correspondences might explain why the non-Japanese speakers in Kunihira’s (1971) study were better able to guess the meanings of Japanese antonyms (e.g., the Japanese for brightdark, rough-smooth, walk-run, heavy-light, narrow-wide, up-down) when these were spoken to them expressively rather than in monotone (i.e., because of the additional acoustic features provided through prosody). 


\section{CORRESPONDENCES AND SYMBOLISM}

In conclusion, cross-sensory correspondences involving the perceptual features of speech sounds appear to have the potential to support variants of an additional form of sound symbolism, that is, prosodic sound symbolism. These correspondences seem to help ensure the 'fittingness' with which words are spoken (the medium) for the message being communicated in the words.

\section{Cross-Sensory Correspondences and Visual Symbolism}

Cross-sensory correspondences are bi-directional, allowing either of two associated features to induce the other. For example, pitch and brightness enjoy the same correspondence with each other whether this is probed with a sound or with a visual stimulus. Furthermore, regardless of the direction in which cross-sensory features are induced, the same core correspondences emerge whatever the sensory channel through which a stimulus contrast is encoded (e.g., L. Walker, P. Walker, \& Francis, 2012). Assuming linguistic stimuli are able to exploit the full range of cross-sensory correspondences, then additional forms of symbolism in language, extending beyond the sounds of words, should be possible. An obvious candidate is the visual equivalent of sound symbolism.

The visual equivalent of lexical sound symbolism would involve the structural visual features of the letters in a word being appropriate for the meaning of the word. For example, the names of high-pitched sounds (e.g., trill) and bright visual stimuli (e.g., glisten) would comprise thin and angular letterforms, because thinness and angularity correspond with high pitched and bright. With limited success, Koriat and Levy (1979) explore this possibility (which they refer to as figural symbolism) in relation to the shapes of Chinese ideographic characters. For written languages such as English, however, which have evolved to represent 


\section{CORRESPONDENCES AND SYMBOLISM}

words primarily via their speech sounds, instances of the visual equivalent of lexical sound symbolism are much less likely.

The visual equivalent of prosodic sound symbolism is a different matter however. Though the letter sequences identifying English words are constrained to represent words as they are spoken and heard, there are many ways in which the same word can be realised visually, just as there are many ways in which the same word can be spoken. Thus, in the visual equivalent of prosodic sound symbolism, it will be the size, colour, and typeface in which a printed word appears that provide the cross-sensory features appropriate for the concept to which the word refers.

\section{The visual equivalent of prosodic sound symbolism.}

There is already extensive evidence for visual symbolism, albeit based on a relatively transparent association between visual form and word meaning. This is evidence confirming that the printed size of text induces congruity effects when people have to classify words according to the magnitude of the items they name. The print size in which a digit or number word appears induces congruity effects when people classify a named item according to its numerical magnitude (Algom, Dekel, \& Pansky, 1996; Besner \& Coltheart, 1979; Fitousi \& Algom, 2006; Foltz, Poltrock, \& Potts, 1984; Hatta, 1983; Henik \& Tzelgov, 1982; Tzelgov, Meyer, \& Henik, 1992; Vaid, 1985). Print size also impacts on judgements relating to the physical sizes of named objects. Foltz, Poltrock, and Potts (1984), and Rubinsten and Henik (2002) asked readers to indicate which of two named items was larger (smaller) than the other. They observed participants to respond more quickly and accurately when the size of the text in which the names appeared was congruent (e.g., elephant - mouse), rather than incongruent (e.g., elephant - mouse), with the relative sizes of the named items. And in the context of a picture-sentence verification task, Reich and Cherry (1979) observed participants 


\section{CORRESPONDENCES AND SYMBOLISM}

to respond more slowly when the relative text size of individual words was incongruent with the situation depicted in the picture. For example, participants were slower to verify that a boy in a picture was taller than a girl in the same picture when their proper nouns were printed as 'John is taller than Sue' rather than as 'John is taller than Sue.' They were slower also when the adjective appeared in an incongruent print size (e.g., 'taller'), rather than a congruent print size (e.g., ‘taller’). Finally, Coulter and Coulter (2005) show how presenting the sale price for an item in a smaller print size than the original price appearing alongside it, induces shoppers to feel they are getting a better deal (i.e., because the sale price feels even smaller in magnitude).

Other examples of visual symbolism are less transparent in nature, and it is with these that cross-sensory correspondences have the best opportunity to reveal their influence (e.g., Childers \& Jass, 2002; Doyle \& Bottomley, 2004, 2009; Pan \& Schmitt, 1996; P. Walker, Smith \& Livingston, 1986). For example, Doyle and Bottomley (2004), and Pan and Schmitt (1996) show how people are more likely to feel favourably towards, enquire about, and purchase, products whose branded names appear in a typeface with appropriate cross-sensory features (e.g., a smooth and thick typeface to match the smoothness and thickness desired of chocolate). Doyle and Bottomley (2009) also demonstrate that the cross-sensory features inherent in a typeface can transfer to the item named in the text (e.g., to a new product category). For example, people expect a new brand of chocolate to be smoother and thicker when the typeface in which its brand name appears has these cross-sensory features.

These few demonstrations of visual symbolism relate to the encoding of text. Iwaraha, Hatta, and Maehara (2003) provide intriguing evidence for a similar form of symbolism in the production of text (i.e., writing to dictation). Japanese provides alternative scripts (i.e., Kanji, Hiragana, \& Katakana) in which many words can be written, and Iwahara et al. 


\section{CORRESPONDENCES AND SYMBOLISM}

confirm that these scripts differ in their cross-sensory features. For example, whereas text in Kanji and/or Katakana appears relatively angular, cool, hard, and fast, text in Hiragana appears relatively round, warm, soft, and slow. Of particular interest in the present context, Iwaraha et al. show how writers are automatically inclined to choose to write in the script whose cross-sensory features match the meaning of the word they are being asked to write. This, of course, is not too distant from observations made in early studies of the universal connotative meanings of elementary stimulus features (e.g., Karwoski, Odbert \& Osgood, 1942; Lundholm, 1921; Osgood, 1960; Poffenberger \& Barrows, 1924; Scheerer \& Lyons, 1957). In particular, when people draw the visual imagery they experience when listening to short musical selections, they choose to draw lines and forms that are more angular (sharper), brighter, smaller, and thinner, the higher in pitch and/or faster in tempo is the music (Karwoski, Odbert, \& Osgood, 1942; Kussner \& Leech-Wilkinson, 2013). That is, they draw lines and forms having the same cross-sensory features as the music they are drawing.

(figure 1 here)

Figure 1. The two contrasting typefaces found to induce typographic congruity effects in Lewis and P. Walker's (1989) study of the speeded classification of words.

P. Walker (2012) and L. Walker, P. Walker, and Francis (2012) examined the crosssensory features associated with visual angularity (pointiness), and observed the same core set of correspondences observed elsewhere, including the correspondence between visual angularity and auditory pitch. Their participants judged simple novel shapes that were angular to be brighter, faster, harder, higher in pitch, lighter in weight, sharper, and smaller, 


\section{CORRESPONDENCES AND SYMBOLISM}

than their curved counterparts. With the visual equivalent of prosodic sound symbolism in mind, it is important to note that the same clustering of cross-sensory features also distinguishes thin, pointy typefaces (e.g., Palatino Italic) from rounded typefaces (e.g., Cooper Black) (cf. Figure 1) (Lewis \& P. Walker, 1989; P. Walker, Smith, \& Livingston, 1986). Lewis and P. Walker (1989) show, for example, how people judge Palatino Italic to be, amongst other things, bright, fast, and light in weight, whereas they judge Cooper Black to be dull, heavy, and slow, all of which is in line with the clustering of features observed in cross-sensory correspondences elsewhere. Lewis and P. Walker went on to take advantage of these contrasting connotations of the two typefaces to demonstrate a visual equivalent of prosodic sound symbolism, showing how the cross-sensory features of a typeface can intrude on reading during the speeded semantic classification of words. Their participants were quicker to classify a word according to the relative weight or speed of the concept it named when the word appeared in a typeface that had congruent, rather than incongruent, crosssensory features (e.g., they were relatively quick to classify mouse as referring to a light weight animal when it appeared in Palatino Italic, than when it appeared in Cooper Black).

\section{Experiments}

Encouraged by these initial demonstrations of a visual equivalent of prosodic sound symbolism based on cross-sensory correspondences, the experiments reported below were designed to provide more systematic and compelling evidence for the same by extending Lewis and P. Walker's (1989) study of the speeded classification of words.

Because auditory pitch figures highly both in known cross-sensory correspondences and in sound symbolism, it provides the basis on which words were classified in all the experiments reported below. That is, words were classified according to whether the concept 


\section{CORRESPONDENCES AND SYMBOLISM}

they name is associated with a high-pitched sound (e.g., squeal, piccolo) or a low-pitched sound (e.g., thud, tuba). ${ }^{2}$ The alternative typefaces in which test words appeared, though task irrelevant, were chosen to have cross-sensory features that, according to known correspondences, are either congruent or incongruent with the level of pitch referred to by each word. The focus was on typefaces contrasting physically in the thinness of their letterforms, because thinness is especially salient in typeface design (see, for example, van Leeuwen, 2006), and because it enjoys a strong correspondence with auditory pitch that gives rise to congruity effects in the speeded classification of simple stimuli (e.g., Evans \& Treisman, 2010). Indeed, in the Farsi language, sounds of contrasting pitch are labelled as being thin or thick, rather than as high or low (Dolscheid, Shayan, Majid, \& Casasanto, 2013). Furthermore, 3- to 4-month-old infants are sensitive to the correspondence between thinness and high auditory pitch, even when the language of their culture (e.g., Dutch) labels sounds of contrasting pitch as high and low (Dolscheid, Hunnius, Casasanto, \& Majid, 2014).

In Experiments 2 - 4, the surface brightness of the text (i.e., whether it appears as black text on a grey background, or as white text on a grey background) was manipulated as a second task irrelevant visual feature, additional to the manipulation of typeface. There were two reasons for manipulating brightness. First, when appearing in conventional black-onwhite format, text differs physically in overall brightness according to the thinness of the typeface (i.e., the amount of black 'ink' per unit surface area is less when text appears in the thinner Palatino Italic, than when it appears in the thicker Cooper Black). Because of this, any effects arising from the correspondence between thinness and pitch need to be

\footnotetext{
${ }^{2}$ Lewis and Walker (1989) did not explore whether typefaces have connotations linking them to high- or low-pitch sounds (though they did have participants rate them on an abstract highlow dimension). Nor did they explore a version of the speeded classification task in which the basis for classification was the level of auditory pitch referred to by a word.
} 


\section{CORRESPONDENCES AND SYMBOLISM}

dissociated from effects that might arise from such variations in brightness. Second, as a feature dimension involved in the core set of cross-sensory correspondences, brightness itself enjoys a strong association with auditory pitch. Not only are higher pitched sounds perceived to be brighter than lower pitched sounds, people also expect darker objects to make lower pitched sounds than brighter objects (L. Walker, P. Walker \& Francis, 2012). In addition, in some languages (e.g., Norwegian), as in musicology, high and low pitch sounds are labelled as being bright and dark, respectively. Indeed, 10-month-old (Japanese) and 30- to 36month-old (Canadian) infants are sensitive to a non-verbal correspondence between auditory pitch and brightness (Haryu \& Kajikawa, 2012; Mondloch \& Maurer, 2004). Therefore, with the brightness of letters potentially providing a basis for visual symbolism through its correspondence with pitch, participants might also find it easier to classify words according to the pitch of the concepts they name when the words appear with a congruent level of brightness (i.e., the names of high-pitched concepts as white-on-grey text, and the names of low-pitched concepts as black-on-grey text), rather than with an incongruent level of brightness (i.e., the names of high-pitched concepts as black-on-grey text, and the names of low-pitched concepts as white-on-grey text).

In general, task-irrelevant variations in both the thinness and brightness of letter strokes were given the opportunity to induce congruity effects confirming that cross-sensory correspondences can support a type of visual symbolism equivalent to prosodic sound symbolism.

\section{Pairs of typefaces contrasting in the thickness of their letter strokes and their cross-sensory associations with auditory pitch}

For the speeded classification experiments to follow, pairs of typefaces were required that contrasted in the cross-sensory feature on which words were to be classified. That is, 


\section{CORRESPONDENCES AND SYMBOLISM}

pairs of typefaces were needed that contrasted in the level of auditory pitch (i.e., high or low) with which they were associated through cross-sensory correspondences. Primary focus was on pairs of typefaces contrasting physically in the thinness-thickness of their letter strokes, with known cross-sensory correspondences indicating that the typefaces should then contrast in the pitch of the sounds with which they are associated (i.e., with the thinner typeface being judged to be higher in pitch). The main task-irrelevant manipulation in each speeded classification experiment would then involve to-be-classified words appearing either in a typeface with thin (high pitch) letter strokes, or in a typeface with thick (low pitch) letter strokes. In this way, congruent and incongruent combinations of typeface and word meaning were to be created (i.e., with the typeface and word either sharing the same relative value for auditory pitch, or having contrasting values).

Cooper Black and Palatino Italic. Pairs of physically contrasting typefaces were chosen by the author from those available in popular word processing packages (see Figure 2). For the first experiment, Cooper Black and Palatino Italic were selected, in part because of their successful use in an earlier study (Lewis \& P. Walker, 1989).

Swiss Light and Swiss Light Italic. The relative thinness of Palatino Italic, compared to Cooper Black, is conflated with its italicisation (i.e., the obliqueness of the 'vertical' letter strokes). The selection of two further typeface pairings addressed this conflation, with one pair contrasting only in the italicisation of one of the typefaces, and a further pair contrasting only in the thickness of their letter strokes. For the first of these additional pairings two different fonts derived from the same typeface were selected, comprising Swiss Light and Swiss Light Italic. Because they are different fonts derived from the same typeface (Swiss), they are very closely matched in most visual respects, including 


\section{CORRESPONDENCES AND SYMBOLISM}

their thinness. ${ }^{3}$ Using this typeface pairing in a speeded classification experiment was expected to reveal the extent to which it might be the italicisation of Palatino Italic, rather than its relative thinness, that is responsible for the congruity effects observed when it is paired with Cooper Black.

Swiss Black and Swiss Light. Swiss Black and Swiss Light were selected as a further pairing. As two fonts derived from the same typeface, they differ only in the physical thickness of their letter strokes (the former being a bold font version of the typeface). Using this pairing as alternatives fonts in which test words could appear during speeded classification was expected to confirm that the thinness-thickness of letter strokes can induce a typographic congruity effect without any involvement from italicisation.

Perpetua and Chalkboard. Finally, Perpetua and Chalkboard were added to the sample of paired typefaces. The contrast in the physical thickness of these two typefaces is largely confined to the ends of the letter strokes, giving the impression of two typefaces contrasting primarily in their pointiness. In the end, this pairing was not used in the experiments reported here, but in experiments to be reported separately.

To reiterate, the intention was not to provide a comprehensive investigation of the cross-sensory correspondences evident in a representative sample of all text typefaces. Instead, the purpose was twofold. First and foremost, to confirm that people are sensitive to the contrasting physical thinness-thickness of paired typefaces and on this basis will associate the typefaces with contrasting levels of auditory pitch. Second, to confirm that the other cross-sensory features associated with this typographic contrast are those expected on the

\footnotetext{
${ }^{3}$ When typographers create a style for a new typeface, they normally also create variations, typically including light, bold, and italic versions of the typeface. These variations are referred to as fonts rather than as typefaces.
} 


\section{CORRESPONDENCES AND SYMBOLISM}

basis of known cross-sensory correspondences (e.g., that the thinner typeface in each pairing would be judged to be brighter, faster, lighter in weight, and smaller than its thicker counterpart). Observing this would provide some important reassurance regarding the involvement of cross-sensory correspondences in any congruity interactions between thinness and pitch observed in the experiments to follow, and would strengthen the case for interpreting these interactions as a visual equivalent of sound symbolism.

\section{Method}

Materials.

Each of the seven typefaces was rated on seven 7-point scales anchored at their ends with bi-polar adjectives representing feature dimensions involved in the core set of crosssensory correspondences. These bi-polar adjectives were: thin-thick, light-heavy, high-low (pitch), sharp-blunt, small-big, fast-slow, and bright-dull.

Booklets were prepared with each page devoted to the evaluation of one typeface, and with the seven pages (typefaces) randomly ordered for each participant. The full lowercase alphabet was printed solid set, and centred at the top of each page. The print size varied slightly for different typefaces to ensure their $\mathrm{x}$-heights were within 6 - $7 \mathrm{~mm}$ and appeared to be matched for perceived size. The 7 rating scales were printed in random order below each typeface, with the order determined afresh for each page. The midpoint on all the scales was labelled NEITHER, and successively more extreme points were labelled SLIGHTLY, QUITE, and VERY, respectively. Across the set of typefaces the high-low (pitch) scale was equally likely to run from left-right or right-left. The left-right ordering of each of the other scales on a page was varied so that three or four were correspondingly aligned with the highlow scale (e.g., high and bright both on the left), and four or three were not (e.g., high on the 
CORRESPONDENCES AND SYMBOLISM

left, bright on the right). Across participants the left-right ordering of each rating scale was counterbalanced for each typeface.

\section{Participants.}

Twenty-two Lancaster University students (16 females), aged from 18 to 39 yrs (mean age $=21.2$ yrs), volunteered to take part in this preliminary study in exchange for course credit or payment of $£ 3$.

\section{Procedure.}

Each participant was given a single A4 sheet, separate from the questionnaire booklet, on which the full lowercase alphabet was printed in all seven typefaces. They were advised that each individual typeface was to be judged against this small set of typefaces (i.e., "Judge the qualities each typeface possesses relative to the other typefaces being considered"). They were then asked to work through their booklet and rate each typeface on every scale, marking the integer scale position judged most appropriate (e.g., "How fast or slow does this typeface seem to be to you?”). With regard to the high-low (pitch) scale they were asked to "Imagine this typeface came to life (became animated) and made a sound: How high or low in pitch would this sound be?” In general, participants were advised not to dwell for too long on any of the typeface ratings, but to register their immediate impression.

\section{Results}

Participants' mean ratings for each typeface on each scale were compared against the NEITHER rating of 4.0 (using a single sample $t$-test). The mean ratings on each scale for the two typefaces in a pairing were then compared against each other (using a paired samples $t$ test). 


\section{CORRESPONDENCES AND SYMBOLISM}

The mean ratings of each pair of typefaces on each scale are shown in Figures 2A-2D, along with a graphic indication of the outcome of each statistical test. Further details of the ratings are provided in Table 1 , and details of the statistical analyses are available in the Appendix.

(figures 2A-2D here)

Figure 2. Mean ratings for each pair of typefaces (A, B, C, \& D) on each scale. Solid symbols indicate mean ratings deviating significantly from the NEITHER rating of 4.0, and open symbols indicate non-significant deviations from the NEITHER rating. All the ratings for each pair of typefaces differed significantly from each other, except those connected by a horizontal line (all 2-tailed tests) (see the Appendix for further details).

(table 1 here)

\section{Participants' sensitivity to the contrasting physical thinness-thickness of paired}

typefaces. Figures 2A - 2C confirm that the typeface with thinner letter strokes in each of the relevant three pairings was indeed judged to be significantly thinner than the thicker typeface with which it was paired. For two of the pairings (i.e., Cooper Black - Palatino Italic, Swiss Black - Swiss Light), the contrast in their judged thinness was the strongest contrast. In the case of the Perpetua - Chalkboard pairing, though the strongest contrast was in their judged sharpness, the contrast in their judged thinness was almost as pronounced. 


\section{Are the cross-sensory features associated with contrasting typographic thinness-}

\section{thickness those expected on the basis of known correspondences, including auditory pitch?}

Given the rationale for the speeded classification experiments, it is reassuring to note that for the same three typeface pairings the thinner typeface differed from its thicker counterpart by being associated with higher levels of auditory pitch. Its other cross-sensory features were in line with the clustering of features observed in cross-sensory correspondences, with each of the thinner typefaces being judged to be significantly brighter, faster, higher (in pitch), lighter in weight, and smaller, than its thicker counterpart. For many of these cross-sensory features not only did the paired typefaces have significantly different ratings from each other, they

each also differed significantly from the NEITHER value on the scales. The few exceptions to these generalisations are indicated graphically in Figure 2.

Cross-sensory features associated with italicisation. With regard to the pair of typefaces differing only in the italicisation of one of them, that is, Swiss Light - Swiss Light Italic, Figure 2D confirms that both typefaces were judged to be significantly thin, and almost equally so, and that their other judged features were consistently located towards those ends of the scales predicted to correspond with thin. Nevertheless, the italicisation of Swiss Light did moderate the ratings, generally shifting them even further towards the 'thin end' of the scales, though this shift was significant only for ratings on the fast-slow and highlow (pitch) scales.

\section{Discussion}

The general nature of the clustering of cross-sensory features observed when typefaces contrasting in the thinness of their letter strokes are examined is entirely consistent with the clustering observed when cross-sensory correspondences are examined with other types of stimuli (e.g., when the cross-sensory features of simple sounds varying in pitch are 


\section{CORRESPONDENCES AND SYMBOLISM}

assessed). Thus, thinner typefaces are judged to be higher in pitch and, like higher-pitched sounds, to be brighter, faster, lighter in weight, sharper, and smaller, than thicker typefaces (see Table 1, in which the ratings have been arranged to highlight these alignments with auditory pitch).

Observing the predicted differences in judged pitch within the three pairs of typefaces contrasting in thinness (Cooper Black - Palatino Italic, Swiss Black - Swiss Light, and Chalkboard - Perpetua) recommends switching between the two typefaces in a pairing as a task-irrelevant manipulation during the speeded classification of words. Specifically, adopting these paired typefaces as alternatives in which to present words has the potential to reveal visual symbolism when the words are being classified according to the pitch of the concepts they name. Because this is particularly the case for the first two of these typeface pairings, where the contrast in the judged thinness of the paired typefaces is the most pronounced contrast, these two pairings were used here, alongside the pairing contrasting in italicisation.

\section{Experiment 1: Thinness with pitch}

Participants performed a speeded classification task in which they classified words according to the pitch of the sound (i.e., high or low) associated with the concept they named. In separate sub-experiments, two types of named concept were examined. In Experiment 1a, the names of musical instruments making relatively high-pitched or relatively low-pitched sounds were chosen as test words (e.g., trumpet and tuba, respectively). In Experiment 1b, the names of relatively high-pitched or relatively low-pitched sounds were chosen as test words (e.g., shriek and thud, respectively). Named sounds were selected for which pitch is 


\section{CORRESPONDENCES AND SYMBOLISM}

an especially salient intrinsic feature, as confirmed by consulting dictionary definitions of their names.

As a task-irrelevant manipulation, it was arranged for the words to appear in two alternative typefaces contrasting in the thinness of their letter strokes. Palatino Italic and Cooper Black were chosen for this purpose. Consistent with known correspondences involving thinness, the preliminary study confirmed that the thinness of Palatino Italic associates it with high-pitched sounds, whereas the thickness of Cooper Black associates it with low-pitched sounds. Assuming there exists a visual equivalent of prosodic sound symbolism, participants were expected to classify words associated with high-pitched sounds relatively more easily when they appeared in the thinner of the two typefaces (i.e., Palatino Italic), and to classify words associated with low-pitched sounds relatively more easily when they appeared in the thicker of the two typefaces (i.e., Cooper Black).

\section{Method}

In Experiment 1a, the names of musical instruments making relatively high-pitched sounds were flute, piccolo, trumpet, and violin. The names of instruments making relatively low-pitched sounds were bassoon, doublebass, timpani, and tuba. In Experiment 1b, the names of relatively high-pitched sounds were chirp, ping, shriek, and squeal. The names of relatively low-pitched sounds were boom, drone, groan, and thud.

Although participants were to read the test words, rather than hear them being spoken, the acoustic features of the words themselves, as imagined by participants, have the potential to influence the classification decisions. Particularly influential in this respect are the acoustic features of a word's vowels, especially the acoustic frequencies of each vowel's first and second formant. With the frequency of the second formant having most influence in 


\section{CORRESPONDENCES AND SYMBOLISM}

determining the cross-sensory features of a vowel sound, it was especially important to monitor the involvement of this frequency. With this in mind, all the words to be used as test stimuli were indexed for the average position of the tongue (front - back) across all their constituent vowels. ${ }^{4}$ The position of the tongue for an individual vowel was scored as 1 (front), 2 (central), or 3 (back), reflecting a shift from higher $\mathrm{f}_{2}$ to lower $\mathrm{f}_{2}$. One might expect, therefore, that test words with relatively high average scores for vowel position would be more easily classified as being associated with lower pitch referents, and vice versa. In addition, the average vowel height for each test word also was indexed, with each vowel scored as an integer from 1 (close) to 4 (open). With higher scores for vowel height reflecting a shift from low $\mathrm{f}_{1}$ to high $\mathrm{f}_{1}$, it would be expected that test words with relatively high average vowel height scores would be more easily classified as being associated with higher pitch referents. The complication here, however, is that to the extent that it is the frequency separation of $f_{1}$ and $f_{2}$ that determines a vowel sound's cross-sensory features, the opposite effect of vowel height could be predicted. Table 2 shows the average vowel position and vowel height scores for each test word used in the present study.

(table 2 here)

The sounds referred to by the words also vary in their characteristic loudness, and this could be confounded with their characteristic pitch, especially in the case of the names of musical instruments. If confounded with pitch, most likely with low pitch sounds tending to be louder, then it is conceivable that loudness might inform participants' classification

\footnotetext{
${ }^{4}$ I am very grateful to Padraic Monaghan for scoring all the test words for average vowel position and average vowel height.
} 


\section{CORRESPONDENCES AND SYMBOLISM}

decision, allowing an association between thinness-thickness and loudness (with thicker being louder) to yield a typographic congruity effect comparable to that predicted for pitch. To assess any effects arising from a confounded variation in the characteristic loudness of the sounds, two groups of additional participants ( $\mathrm{N}=23$ for each group) rated the two sets of words on a 9-point scale running from quiet (1) through to loud (9). The average loudness ratings are shown in Table 2. Repeated measures ANOVA confirmed a significant difference in the judged loudness of the two sets of musical instruments, $F(1,22)=39.26, M S E=3.03$, $\eta p^{2}=.64, p<.001$, with the lower pitch instruments being judged to make louder sounds than higher pitch instruments, mean loudness ratings of 6.36 and 4.75, respectively. There was not a significant difference in the judged loudness of the low and high pitch named sounds, $F(1,22)=2.33, M S E=6.54, \eta p^{2}=.09, p=.14$, with mean loudness ratings of 5.74 and 5.16, respectively.

For each sub-experiment, crossing item name (8 levels) and typeface (2 levels) yielded 16 different test stimuli. These test stimuli were presented in a different random order for each participant in each of eight blocks of trials. In this way, every participant completed 128 trials.

The background colour of the screen remained white throughout, and the words appeared in black. ${ }^{5}$ The $x$ height for each typeface was 6 - $7 \mathrm{~mm}$. A fixation point was not provided and there was no other visual indication on the screen marking the central location at which each stimulus would appear. Participants viewed the screen from $55 \mathrm{~cm}$.

Each test word remained visible until the participant responded by pressing either the ' $z$ ' key or the '/' key to indicate the relative level of pitch (high or low) associated with the named concept. Participants were asked to respond as quickly as possible, but without

\footnotetext{
${ }^{5}$ Manipulating text brightness is introduced in Experiment 2.
} 


\section{CORRESPONDENCES AND SYMBOLISM}

making unnecessary mistakes. No feedback was provided regarding the accuracy of their responses, and an interval of 3 s elapsed before the next test word appeared. The assignment of the two keys to high and low pitch was counterbalanced across participants.

Stimulus presentation and response monitoring were controlled by a Dual $2 \mathrm{GHz}$ Apple PowerMac G5 (interfaced with an Apple A1038, 1680 x 1050 cinema back-lit LCD display), running version 2.1.1 of the PsyScript experiment generator.

\section{Participants.}

Thirty-eight undergraduate and postgraduate Lancaster University students (25 females), aged from 18 to 32 yrs (mean age = 20.6 yrs), volunteered to participate in return for $£ 3$. All but one of the participants were right-handed by self-report. Nineteen students completed each of Experiment 1a and Experiment 1b.

\section{Results}

Analysing response accuracy. The task instructions emphasised the need for participants to maintain high levels of accuracy so that the focus would be on response speed as a dependent measure. Not surprisingly, therefore, levels of accuracy were consistently high in all the experiments being reported here, and so simple non-parametric analyses of accuracy focussed on confirming the presence, or otherwise, of a typeface congruity effect (and of a brightness congruity effect where relevant). An alpha level of 0.05 was used for all statistical tests, and only 2-tailed $p$ values are referred to.

Analysing response speed. Prior to statistical analysis, the response times (RTs) were subject to reciprocal transformation (i.e., converted to response speed) to improve the normality of the residuals. R (R Core Team, 2012) and lme4 (Bates, Maechler \& Bolker, 
2014) were used to perform linear mixed effects analysis of the relationship between response speed and the congruence between auditory pitch and typeface (and brightness where relevant in later experiments). The intercepts for participants and words were treated as having random effects on response speed. For all analyses of this kind reported below, visual inspection of residual Q-Q plots did not reveal any departures from normality that would jeopardise the analysis.

Likelihood ratio tests were used to assess the significance of any impact an individual factor of interest had on response speed, comparing models that differed only in the inclusion of this factor in one of them. ${ }^{6}$ All models included TRIAL, PITCH, VOWEL HEIGHT,

6 The models used in the linear mixed effects analyses, that included the congruence effect of interest (underlined), are listed below. Where TYPEFACE CONGRUENCE and BRIGHTNESS CONGRUENCE were being explored, additional models were considered in which word was treated as having random slopes (see below). model $=\operatorname{lmer}($ reciprocalRT $\sim$ TRIAL + PITCH + TYPEFACE + BRIGHTNESS + VOWELHEIGHT + VOWELPITCH + TYPEFACE CONGRUENCE + (1/participant) + (1/word), and then again with (1 - TYPEFACE CONGRUENCE/word) model $=\operatorname{lmer}($ reciprocalRT $\sim$ TRIAL + PITCH + TYPEFACE + BRIGHTNESS + VOWELHEIGHT + VOWELPITCH + BRIGHTNESS CONGRUENCE + (1/participant) + (1/word), and then again with (1 - BRIGHTNESS CONGRUENCE/word) model $=\operatorname{lmer}($ reciprocalRT $\sim$ TRIAL + PITCH + TYPEFACE + BRIGHTNESS + VOWELHEIGHT + VOWELPITCH + VOWELHEIGHT CONGRUENCE + (1/participant) + (1/word)

model $=\operatorname{lmer}($ reciprocalRT $\sim$ TRIAL + PITCH + TYPEFACE + BRIGHTNESS + VOWELHEIGHT + VOWELPITCH + VOWELPOSITION CONGRUENCE + (1/participant) + (1/word)

model $=\operatorname{lmer}($ reciprocalRT $\sim$ TRIAL + PITCH + TYPEFACE + BRIGHTNESS + VOWELHEIGHT + VOWELPITCH + TYPEFACE CONGRUENCE + LOUDNESS + LOUDNESS:TYPEFACE + (1/participant) + (1/word) 
VOWEL POSITION, BRIGHTNESS (except Experiment 1), and TYPEFACE as fixed effects. Different congruity interactions with PITCH were then added in turn and the significance of their impact on response speed determined. These congruity factors were: TYPEFACE CONGRUENCE, BRIGHTNESS CONGRUENCE (except Experiment 1 where brightness was not manipulated), VOWEL HEIGHT CONGRUENCE, and VOWEL POSITION CONGRUENCE. Because the variations in vowel height and vowel position were not managed for the purpose of assessing any congruence effects they might induce, but rather were accidental in nature, there was little interest in exploring such congruence effects themselves in detail. On the one occasion when vowel height and vowel position interacted significantly with pitch, primary interest was on the relevance of this for the typeface congruity effect. For this reason, steps were taken to confirm that the typeface congruity effect was unaffected by the presence of a vowel-induced congruity effect, thus confirming that the former could not be better explained as an interaction between the features of the vowels in a word and the pitch of the sound it named. Finally, a different type of congruence was assessed, namely, that involving the LOUDNESS X TYPEFACE interaction. The significance of this congruence effect was assessed after adding LOUDNESS to the basic model, that also included TYPEFACE CONGRUENCE. As explained already, this was undertaken to assess the presence of a congruity interaction between the thinness-thickness of a typeface and the loudness, rather than the pitch, of the named sound. Again, on the one occasion where a significant loudness congruence effect was observed, steps were taken to check that it had no implications for the typeface congruity effect, confirming that the latter could not be better explained as a loudness congruity effect. In summary, the main purpose of assessing the vowel height, vowel position, and loudness congruity effects was to see if they provided an alternative explanation for what would otherwise appear to be a typeface congruity effect. 


\section{CORRESPONDENCES AND SYMBOLISM}

Finally, unstandardised and standardised estimates of effect size are reported for typeface and brightness congruence, the former estimates in terms of the extent of change in response speed (and mean response time), the latter in terms of the percentage of additional variability explained by adding the congruence factor to the model. Omega-squared $\left(\omega^{2}\right)$ as an estimate of variability explained by a model was derived for this purpose. ${ }^{7}$

(table 3 here)

The results are summarised in Table 3.

\section{Experiment 1a: Musical instruments.}

Accuracy. The overall error rate was 2.8\%. Wilcoxon’s Signed Ranks Test confirmed significantly higher levels of accuracy on typeface congruent trials than on typeface incongruent trials, $p=.021$.

Response speed. The average correct response speed was 1.45 responses/sec, which translates back to an equivalent RT of $691 \mathrm{~ms}$.

Typeface congruence had a significant effect on response speed, $\chi^{2}(1)=39.22, p$ $<.0001$, raising it by .068 responses/sec $(\mathrm{SE}=.010)$, reflecting a 34 ms reduction in RT. Inspection of the coefficients for typeface congruence confirmed that it facilitated decision speed for every word (range $=.059$ to .073 decisions/sec). Monitoring the impact on $\omega^{2}$ of adding typeface congruence to the model revealed that an extra $1.1 \%$ of the variance was

\footnotetext{
7 The R code used to calculate $\omega^{2}$ is: 1-var(residuals(m))/(var(model.response(model.frame(m))))
} 


\section{CORRESPONDENCES AND SYMBOLISM}

explained (with $\omega^{2}$ changing from 32.2 to 33.3\%). Neither vowel position nor vowel height interacted significantly with pitch, $\chi^{2}(1)=1.80, p=.18$, and $\chi^{2}(1)=1.46, p=.22$, respectively. Similarly, loudness did not interact significantly with typeface, $\chi^{2}(1)=2.59, p$ $=.10$.

\section{Experiment 1b: Names of sounds.}

Accuracy. The overall error rate was 1.6\%. Wilcoxon’s Signed Ranks Test confirmed significantly higher levels of response accuracy on typeface congruent trials than on typeface incongruent trials, $p=.04$.

Response speed. The average correct response speed was 1.50 responses/sec, which translates back to an equivalent RT of $666 \mathrm{~ms}$.

Typeface congruence had a significant effect on response speed, $\chi^{2}(1)=57.20, p$ $<.0001$, raising it by .086 responses/sec $(\mathrm{SE}=.011)$, reflecting a 37 ms reduction in RT. Inspection of the coefficients for typeface congruence confirmed that it facilitated decision speed for every word (range $=.008$ to .15 decisions/sec). Adding typeface congruence to the model explained an extra $1.7 \%$ of the variance (with $\omega^{2}$ changing from 31.3 to $33.0 \%$ ).

Neither vowel position nor vowel height interacted significantly with pitch, $\chi^{2}(1)=0.01, p$ $=.91$, and $\chi^{2}(1)=0.38, p=.54$, respectively. Similarly, loudness did not interact significantly with typeface, $\chi^{2}(1)=1.11, p=.29$.

\section{Discussion}

The results confirm a typeface congruity effect consistent with the known correspondence between thinness and pitch: Participants classified the names of musical instruments and of sounds relatively more easily when these appeared in a typeface whose thinness was congruent with the level of pitch associated with the concept being named. That 


\section{CORRESPONDENCES AND SYMBOLISM}

is, high-pitched musical instruments and sounds were classified as such relatively more easily when their names appeared in the thinner of the two typefaces (i.e., Palatino Italic), whereas they classified low-pitched musical instruments and sounds relatively more easily when their names appeared in the thicker of the two typefaces (i.e., Cooper Black). It appears, therefore, that the correspondence between thinness and pitch is able to support a form of visual symbolism equivalent to prosodic sound symbolism. The acoustic features of the words themselves, specifically their vowel formants, did not interact with the classification of the named sounds as being either high or low in pitch, and so could not provide an alternative explanation for what is assumed to be a typeface congruence effect.

Preliminary assessment of the typeface pairings (see above) indicated that Palatino Italic and Cooper Black differ in judged size, despite best efforts to match them in this regard by independently adjusting their x-heights. With Cooper Black seeming to be bigger than Palatino Italic, the correspondence between size and pitch also might have contributed to the typeface congruity effect revealed through the interaction between typeface and pitch. Nevertheless, as will be seen from Experiment 4 below, when the contrasting typefaces in which test words appear differ in thinness but not size, a congruity effect in the speeded pitch classification of words is still observed. It seems likely, therefore, that any contribution to the congruity effect observed in Experiment 1 from the correspondence between size and pitch will have, at best, been additional to the contribution from the correspondence between thinness and pitch.

(figure 3 here)

\section{Experiment 2: Thinness and brightness with pitch}




\section{CORRESPONDENCES AND SYMBOLISM}

The correspondence between brightness and pitch, wherein brighter aligns itself with higher pitch, could have contributed to the congruity effect observed in Experiment 1. This is possible because the amount of black ‘ink’ per unit surface area is less when text appears in the thinner Palatino Italic, than when it appears in the thicker Cooper Black. Through its correspondence with pitch, therefore, brightness could have contributed to the congruity effect observed in Experiment 1. This possibility is assessed in Experiment 2 by taking steps to dissociate the brightness of the letters from their thinness.

To separate these two factors, Experiments 1a and 1b were repeated with an additional task-irrelevant visual manipulation. It was arranged for all the words to appear on a mid-grey background, and for each test word to appear either as white-on-grey text, or as black-on-grey text, independently of the typeface in which it appeared (see Figure 3). If elementary shape features distinguishing contrasting typefaces can support visual symbolism, then participants should find it easier to classify words according to the pitch of the concepts they name when the words appear in a congruent typeface, rather than an incongruent typeface. This should occur regardless of the brightness of the letters. Dissociating the manipulation of thinness from changes in brightness also provides an opportunity to explore the possibility of a brightness congruity effect based on the correspondence between brightness and pitch. If brightness can support visual symbolism, then participants should find it easier to classify words according to the pitch of the concepts they name when the words appear in a congruent level of brightness, rather than in an incongruent level of brightness. This should occur regardless of the typeface in which the words appear (i.e., regardless of the thinness of the letter strokes).

\section{Method}




\section{CORRESPONDENCES AND SYMBOLISM}

The design and procedure were the same as for Experiments 1a and 1b, and Palatino Italic and Cooper Black were again the two alternative typefaces in which words appeared. The test words were the same names of musical instruments (Experiment 2a) and sounds (Experiment 2b), and the instructions again required participants to indicate, as quickly as possible, whether the named concepts were associated with high-pitch or low-pitch sounds. However, each test word now appeared sometimes as black-on-grey text, sometimes as white-on-grey text. Crossing test word (8 levels), typeface (2 levels), and text brightness (2 levels) yielded 32 different test stimuli. These were presented to each participant in a different random order in each of three blocks of trials. In total, therefore, each participant completed 96 trials.

\section{Participants.}

Thirty-eight undergraduate and postgraduate Lancaster University students (33 females), aged from 18 to 46 yrs (mean age $=22.29$ yrs), volunteered to participate in exchange for course credit or £3. All but one of the participants were right-handed by selfreport. Nineteen students completed each of Experiments 2a and Experiment 2b.

(table 4 here)

\section{Results}

The results are summarised in Table 4.

\section{Experiment 2a: Musical instruments.}

Accuracy. The overall error rate was $2.35 \%$. There was no overall effect either of typeface congruence, Wilcoxon Signed Rank Test $p=0.77$, or of brightness congruence, Wilcoxon Signed Ranks Test $p=.22$, on response accuracy. 


\section{CORRESPONDENCES AND SYMBOLISM}

Response speed. The average correct response speed was 1.67 responses/sec, which translates back to an equivalent RT of 599 ms.

Typeface congruence had a significant effect on response speed, $\chi^{2}(1)=25.16, p$ $<.0001$, raising it by .065 responses/sec $(\mathrm{SE}=.013)$, reflecting a 22 ms reduction in $\mathrm{RT}$. Inspection of the coefficients for typeface congruence confirmed that it facilitated decision speed for every word (range $=.062$ to .07 decisions/sec). Adding typeface congruence to the model explained an extra $1.0 \%$ of the variance (with $\omega^{2}$ changing from 32.5 to $33.5 \%$ ).

Neither vowel position nor vowel height interacted significantly with pitch, $\chi^{2}(1)=0.65, p$ $=.42$, and $\chi^{2}(1)=2.81, p=.09$, respectively. Though the latter effect was close to being significant, its inclusion in the model had no effect on the typeface congruence effect. Loudness did not interact significantly with typeface, $\chi^{2}(1)=0.43, p=.51$.

Brightness congruence did not have a significant effect on response speed, $\chi^{2}(1)=$ 3.16, $p=.08$, seemingly raising it by .023 responses $/ \mathrm{sec}(\mathrm{SE}=.013)$, reflecting an $7 \mathrm{~ms}$ reduction in RT. Inspection of the coefficients for brightness congruence indicated that it tended towards facilitating decision speed for all but one word (range $=-.002$ to .045 decisions/sec). Adding brightness congruence to the model explained just an extra $0.1 \%$ of the variance (with $\omega^{2}$ changing from 32.5 to $32.6 \%$ ).

\section{Experiment 2b: Names of sounds.}

Accuracy. The overall error rate was 2.2\%. There was no overall effect either of typeface congruence, Wilcoxon Signed Rank Test $p=0.62$, or of brightness congruence, Wilcoxon Signed Ranks Test $p=.11$, on response accuracy.

Response speed. The average correct response speed was 1.84 responses/sec, which translates back to an equivalent RT of $542 \mathrm{~ms}$. 


\section{CORRESPONDENCES AND SYMBOLISM}

Typeface congruence had a significant effect on response speed, $\chi^{2}(1)=11.93, p$ $<.001$, raising it by .049 responses/sec $(\mathrm{SE}=.015)$, reflecting a 15 ms reduction in RT. Inspection of the coefficients for typeface congruence confirmed that it facilitated decision speed for every word (range $=.031$ to .072 decisions/sec). Adding typeface congruence to the model explained an extra $0.5 \%$ of the variance (with $\omega^{2}$ changing from 22.0 to $22.5 \%$ ).

On this occasion, both vowel position and vowel height interacted significantly with pitch, $\chi^{2}(1)=8.46, p=.003$, and $\chi^{2}(1)=5.19, p=.023$, respectively. Crucially, however, including either of these interactions in the model had no effect on the typeface congruence effect. These interactions are considered further in the Discussion section below. Loudness did not interact significantly with typeface, $\chi^{2}(1)=1.10, p=.29$.

Brightness congruence did not have a significant effect on response speed, $\chi^{2}(1)=$ $0.66, p=.42$, seemingly raising it by just .010 responses/sec $(\mathrm{SE}=.015)$, reflecting a $3 \mathrm{~ms}$ reduction in RT. Adding typeface congruence to the model explained only an extra $0.1 \%$ of the variance (with $\omega^{2}$ changing from 22.0 to $22.1 \%$ ).

\section{Discussion}

The results confirm that the contrasting thinness of letters as they appear in Palatino Italic and Cooper Black supports visual symbolism when words are classified according to the level of auditory pitch associated with the concepts they name. It does so independently of any effects that might arise from differences in the overall visual brightness of the text. Thus, the thinness of the typeface in which words appeared interacted predictably with the pitch of the concepts they named regardless of whether the words appeared as black-on-grey text or as white-on-grey text. More specifically, names linked to high-pitched sounds were classified as such relatively more easily when they appeared in the thinner Palatino Italic, 


\section{CORRESPONDENCES AND SYMBOLISM}

whereas names linked to low-pitched sounds were classified relatively more easily when they appeared in the thicker Cooper Black. This was the case both for the names of musical instruments and the names of sounds. Because of the less than optimal distribution of different values for the vowel features across words, it is not easy to observe a systematic pattern to their interaction with pitch. Neither does there appear to be any obvious reason why they interacted with pitch only in this experiment. It is difficult to judge, therefore, whether the interactions are anything other than a type 1 error, or whether they have the potential to provide a viable alternative explanation for what might otherwise appear to be a typeface congruence effect.

Crucially, however, these congruity effects had no bearing on the typeface congruence effect.

Because the brightness of the letters was manipulated independently of typeface, it was possible to assess whether this feature also could interact with the pitch of the named concepts to induce a congruity effect, mediated by the known correspondence between brightness and pitch. There was no evidence for a brightness congruence effect for either response accuracy or response speed.

\section{Experiment 3: Clockwise obliqueness and brightness with pitch}

Letters appearing in Palatino Italic are italicised, giving their 'vertical' strokes a clockwise oblique appearance. The possibility that the obliqueness of Palatino Italic contributed to the typographic congruity effect observed in Experiments 1 and 2, perhaps in addition to its thinness, requires examination. This is reinforced by the fact that when italicisation is isolated from thinness as the only feature distinguishing contrasting typefaces, an italic font is judged to be higher in pitch than an equivalent non-italic font (see the contrast between Swiss Light Italic and Swiss Light in the results of the preliminary assessment of the 


\section{CORRESPONDENCES AND SYMBOLISM}

typeface pairings). This possibility is explored in Experiment 3, where participants are asked to classify named sounds when their names appear in two fonts contrasting only in that one of them is italicised. With this in mind, Palatino Italic and Cooper Black were replaced with Swiss Light Italic and Swiss Light. Because these two fonts are derived from the same typeface, they are comparable in their visual thinness, pointiness, and size. The question then becomes, will participants classify the names of higher pitched sounds relatively more easily when they appear in the italicised font, and the names of lower pitched sounds relatively more easily when they appear in the non-italicised font.

The opportunity was again taken to monitor the correspondence between brightness and pitch to see if it supports visual symbolism. With the to-be-classified words sometimes appearing either as black-on-grey text, and sometimes as white-on-grey text, this correspondence predicts that participants will classify sounds according to their pitch more easily when their names appear with a congruent level of brightness, rather than an incongruent level of brightness. That is, they should find it relatively easy to classify higher pitched sounds when their names appear as white-on-grey text, and lower pitched sounds when their names appear as black-on-grey text.

\section{Method}

The design was essentially the same as for Experiment 2b, with the same words being classified according to the pitch of the sounds they name. Each test word appeared in either Swiss Light Italic or Swiss Light and, independently of this, either as black-on-grey text or as white-on-grey text. Crossing test word (8 levels), typeface (2 levels), and text brightness (2 levels) yielded 32 different test stimuli. These were presented to each participant in a 


\section{CORRESPONDENCES AND SYMBOLISM}

different random order in each of three blocks of trials. In total, therefore, each participant completed 96 trials.

\section{Participants.}

Nineteen undergraduate students at Lancaster University (12 females), aged from 18 to 27 yrs (mean age $=20.1$ yrs), volunteered to participate in return for $£ 3$ or course credit. All of the participants were right-handed by self-report.

(table 5 here)

\section{Results}

The results are summarised in Table 5.

Accuracy analysis. The overall error rate was $2.7 \%$. There was not a significant effect of typeface congruence on accuracy, Wilcoxon Signed Ranks Test $p=0.36$. There was, however, a significant effect of brightness congruence on accuracy, Wilcoxon Signed Ranks Test $p=0.01$, with higher levels of accuracy on brightness congruent trials.

Response speed. The average correct response speed was 1.67 responses/sec, which translates back to an equivalent RT of 599 ms.

Typeface congruence did not have a significant effect on response speed, $\chi^{2}(1)=1.72$, $p=.19$, seemingly raising it by just .019 responses/sec $(\mathrm{SE}=.014)$, equivalent to a $7 \mathrm{~ms}$ reduction in RT. Adding typeface congruence to the model explained only an extra $0.06 \%$ of the variance (with $\omega^{2}$ changing from 40.88 to $40.94 \%$ ). Neither vowel position nor vowel height interacted significantly with pitch, $\chi^{2}(1)=0.01, p=.92$, and $\chi^{2}(1)<0.01, p=.92$, 


\section{CORRESPONDENCES AND SYMBOLISM}

respectively. Similarly, loudness did not interact significantly with typeface, $\chi^{2}(1)=.08, p$ $=.78$.

Brightness congruence had a significant effect on response speed, $\chi^{2}(1)=32.98, p$ $<.0001$, raising it by .084 responses/sec $(\mathrm{SE}=.014)$, reflecting a 29 ms reduction in RT. Inspection of the coefficients for brightness congruence confirmed that it facilitated decision speeds for every word (range $=.076$ to .089 decisions/sec). Adding typeface congruence to the model explained an extra $1.10 \%$ of the variance (with $\omega^{2}$ changing from 40.88 to 41.98\%).

\section{Discussion}

The results indicate that the link between clockwise obliqueness (here as italicised text) and pitch, that was observed in the preliminary assessment of the typeface pairings, does not induce a congruity effect when words are being classified according to the relative pitch of the sounds they name. It would seem, therefore, that it was indeed the thinness of Palatino Italic compared to Cooper Black that induced the typeface congruence effect in Experiments 1 and 2. The frequencies of the vowel formants for the test words failed to influence the classification of the named sounds as being either high or low in pitch.

There can be many reasons for the null finding with regard to the impact of italicisation. For example, a typographic congruity effect might have been absent because the italicisation of Swiss Light is too subtle a visual effect to influence the speeded classification of words, whatever the conceptual basis for the classification. As Figure 2D shows, Swiss Light Oblique Italic and Swiss Light have very similar feature profiles, notwithstanding the presence of significant differences in their judged thinness, speed, and pitch. Both profiles are consistently located towards the high pitch end of the feature dimensions. Despite this, 


\section{CORRESPONDENCES AND SYMBOLISM}

however, P. Walker (2015) confirmed that the italicisation of Swiss Light is able to impact on the speeded classification of words when the basis for classification is more conducive to this. It does so, for example, when named concepts are classified on the basis of the speed of movement with which they are associated (e.g., cheetah - fast, snail - slow). As Cutting (2002) and P. Walker (2015) show, in static visual images, such as drawings and text, introducing clockwise obliqueness is a graphic convention used to convey notions of motion and speed.

What the absence of a typeface congruity effect does indicate on this occasion, however, is that the typeface congruence effect observed in the Experiments 1 and 2 was induced by a combination of the specific typeface manipulation in place (i.e., thinness) and a strong association between this and the conceptual basis on which the words were being classified (i.e., auditory pitch). Were it otherwise, then a typeface congruence effect should have been evident in Experiment 3.

In accordance with the known correspondence between pitch and brightness, participants in Experiment 3 classified the named sounds relatively more accurately and quickly when their names appeared in the corresponding level of brightness (i.e., the names of high-pitched sounds as white-on-grey text, and the names of low-pitched sounds as black-ongrey text). An interesting possibility is that there can be a degree of mutual exclusivity among correspondences in relation to them having an observable impact on behaviour. In which case, it would be because a typeface congruence effect was absent in Experiment 3 that a brightness congruence effect could be observed. This possibility is considered more fully in the General Discussion.

\section{Experiment 4: Thinness and brightness with pitch}




\section{CORRESPONDENCES AND SYMBOLISM}

The potential for a form of visual symbolism to exist based on the thinness of letter strokes is addressed in a slightly different way in Experiment 4. Italicisation is removed from consideration by selecting alternative fonts that, though differing in thinness, do not differ in the orientation of their 'vertical' letter strokes (i.e., neither of them is italicised). The task and stimuli from Experiment $2 \mathrm{~b}$ are adopted (i.e., the same names of sounds were classified according to the pitch of the sounds they name), but now with Swiss Light and Swiss Black replacing Palatino Italic and Cooper Black as the two alternative fonts in which test words appeared. The contrast between these two fonts better isolates thinness as the typographic feature available to interact with pitch to yield a congruity effect.

Text brightness was again included as a task-irrelevant manipulation to see if the core correspondence between brightness and pitch allowed text brightness to interact with pitch to induce an additional congruity effect.

\section{Method}

The design was essentially the same as for Experiment 2b, with the same words being classified according to the pitch of the sounds they name. Each test word sometimes appeared in Swiss Light, and sometimes in Swiss Black and, independently of this, either as black-on-grey text or as white-on-grey text. Crossing test word (8 levels), typeface (2 levels), and text brightness (2 levels) yielded 32 different test stimuli. These were presented to each participant in a different random order in each of three blocks of trials. In total, therefore, each participant completed 96 trials.

\section{Participants.}




\section{CORRESPONDENCES AND SYMBOLISM}

Nineteen undergraduate Lancaster University students (13 females), aged from 18 to 38 yrs (mean age $=21.32$ yrs), volunteered to participate in return for course credit or $£ 3$. All of the participants were right-handed by self-report.

(table 6 here)

\section{Results}

The results are summarised in Table 6.

Accuracy. The overall error rate was 2.9\%. There was not an overall effect either of typographic congruence, Wilcoxon Signed Rank Test $p=0.41$, or of brightness congruence, Wilcoxon Signed Ranks Test $p=.93$, on response accuracy.

Response speed. The average correct response speed was 1.79 responses/sec, which translates back to an equivalent RT of 559 ms.

Typeface congruence had a significant effect on response speed, $\chi^{2}(1)=11.38, p$ $<.0001$, raising it by .056 responses/sec $(\mathrm{SE}=.017)$, reflecting a 19 ms reduction in $\mathrm{RT}$. Inspection of the coefficients for typeface congruence confirmed that it facilitated decision speed for every word (range $=.030$ to .087 decisions/sec). Adding typeface congruence to the model explained an extra $0.5 \%$ of the variance (with $\omega^{2}$ changing from 24.3 to $24.8 \%$ ). Neither vowel position nor vowel height interacted significantly with pitch, $\chi^{2}(1)=0.31, p$ $=.58$, and $\chi^{2}(1)=0.36, p=.55$, respectively. On this occasion, loudness did interact significantly with typeface, $\chi^{2}(1)=6.06, p=.01$. Crucially, however, the typeface congruence effect was not affected by including this interaction in the model. This is consistent with there being no significant difference in the loudness of the high and low pitch 


\section{CORRESPONDENCES AND SYMBOLISM}

sounds named by the words (see above). In addition, apart from the fact that a significant loudness $x$ typeface interaction was not observed in the other two experiments in which the same words were classified (i.e., Experiments $1 \mathrm{~b} \& \mathrm{2b}$ ), the nature of the interaction observed here was not systematic across successive levels of loudness. Furthermore, when loudness was partitioned into just two levels, by aggregating the results for the four loudest levels and the four quietest levels, its interaction with the thinness-thickness of the typefaces was the reverse of what would seem most likely. That is, participants responded more quickly when the names of louder (quieter) sounds appeared in a thinner (thicker) typeface, than when the names of louder (quieter) sounds appeared in a thicker (thinner) typeface (mean RT = 554 and $567 \mathrm{~ms}$, respectively). ${ }^{8}$ It seems clear, therefore, that the variation in the loudness of the named sounds cannot be the basis for an alternative explanation of the observed typeface congruity effect involving the interaction between the thinness-thickness of the font and the pitch of the named sound. Nevertheless, the possibility that the loudness of a named sound will sometimes interact with the thickness of the typeface in which its name appears deserves exploration in studies designed specifically with this purpose in mind.

Brightness congruence did not have a significant effect on response speed, $\chi^{2}(1)=$ 1.42, $p=.23$, seemingly raising it by just .019 responses/sec $(\mathrm{SE}=.017)$, equivalent to a 6 ms reduction in RT. Adding typeface congruence to the model explained only an extra $0.1 \%$ of the variance (with $\omega^{2}$ changing from 24.3 to $24.4 \%$ ).

\footnotetext{
8 The reverse of this pattern was observed in relation to the marginally significant interaction between loudness and typeface in Experiment 1a (i.e., participants tended to respond less quickly when the names of louder (quieter) sounds appeared in a thinner (thicker) typeface, than when the names of louder (quieter) sounds appeared in a thicker (thinner) typeface (mean RT = 709 and 693 ms, respectively).
} 


\section{Discussion}

The results confirm that the thinness of a typeface can interact with the pitch classification of a named sound to induce a congruity effect. As in Experiments 1 and 2, participants responded relatively more quickly when the thinness of the typeface in which a test word appeared was congruent with the pitch of the sound it named. This result indicates again that the correspondence between thinness and pitch is able to support a form of visual symbolism equivalent to prosodic sound symbolism. Consistent with the notion that there can exist a degree of mutual exclusivity among correspondences with regard to them having an observable impact on behaviour, with the reappearance of a typeface congruence effect in this experiment, the brightness of the text no longer interacted with the pitch of the named sound to yield a congruity effect.

\section{General Discussion}

Lexical sound symbolism exploits the feature associations embedded in cross-sensory correspondences. For example, words incorporating relatively high acoustic frequencies (i.e., font/close rather than back/open vowels) are deemed appropriate as names for concepts associated with brightness, lightness in weight, sharpness, smallness, speed and thinness, because higher pitched sounds themselves have these cross-sensory features. Correspondences also support prosodic sound symbolism. For example, speakers raise the fundamental frequency of their voice to emphasise the smallness of the concept they are naming. The conceptual nature of correspondences, along with their functional bidirectionality, indicates they should also support other types of symbolism, including a visual equivalent of prosodic sound symbolism. For example, the correspondence between auditory 


\section{CORRESPONDENCES AND SYMBOLISM}

pitch and visual thinness predicts that a typeface with relatively thin letter strokes will reinforce a word's reference to a relatively high pitch sound (e.g., squeal).

In an initial study, in which four pairs of typefaces were rated for their cross-sensory features, it was confirmed that the thinness-thickness of a typeface's letter strokes endows the typeface with those cross-sensory features predicted on the basis of known correspondences. Text appearing in thinner letter strokes, in addition to be judged to be higher in pitch than text appearing in thicker letter strokes, is also judged to be brighter, lighter in weight, sharper, smaller, and faster.

A series of speeded word classification experiments confirm a visual equivalent of prosodic sound symbolism based on cross-sensory correspondences. Predicted on the basis of the known correspondence between auditory pitch and thinness (with high pitch being aligned with thin), participants classified words according to the pitch of the sound to which they refer (high or low) more easily when the words appeared in a typeface whose letter strokes were correspondingly thin or thick. More specifically, they more easily confirmed that a named sound, or the sound made by a named musical instrument, was relatively high pitched (low pitched) when it appeared in a relatively thin (thick) typeface. As in the case of prosodic sound symbolism, it seems that the manner in which a visual word is presented can reinforce (or undermine) the message the word conveys by engaging with the feature associations embedded in cross-sensory correspondences.

Experiment 3 also provides evidence for visual symbolism based on the correspondence between auditory pitch and brightness. Though introduced primarily as a means of dissociating changes in letter thickness from changes in the overall brightness of text, presenting to-be-classified words either as white-on-grey text, or as black-on-grey text, allowed this additional variant of visual symbolism to be observed. More specifically, 


\section{CORRESPONDENCES AND SYMBOLISM}

participants more easily confirmed that a named sound was relatively high pitched (low pitched) when it appeared in a brighter (darker) format, that is, as white-on-grey (black-ongrey) text rather than as black-on-grey (white-on-grey) text. This robust pitch-brightness congruity effect appeared in relation to both response accuracy and response speed, though now in the absence of a pitch-thinness congruity effect.

As indicated already, this last result raises the possibility that an element of mutual exclusivity exists among correspondences in their influence on speeded classification performance. The author has observed the same apparent mutual exclusivity in an unpublished study in which participants were required to classify simple sounds according to their pitch (high or low) at the same time as watching concurrent visual stimuli appear on a computer screen. As a task irrelevant aspect of the situation, the presentation of a circle accompanied each to-be-classified sound, with the circle varying randomly on a trial-by-trial basis either in brightness (black-on-grey or white-on-grey), height on the screen (high or low), or both brightness and elevation. In the case of participants whose first language was English, when both features of the circle were being varied it was only the elevation of the circle that interacted with pitch to induce a congruity effect. However, when only the brightness of the circle was varied across trials, this too interacted with pitch to induce a congruity effect. The overshadowing of brightness by elevation when both were being manipulated could have arisen for at least two reasons. First, as a changing visual feature it might have been less noticeable than the changes in elevation and, as a consequence, attracted less attention. If the potential of a feature to induce a congruity effect is contingent on the amount of attention it attracts, then the overshadowing of brightness by elevation when both are being manipulated would be explained, as would the fact that when brightness alone was varying it did induce a congruity effect. A second possibility is that, despite being equally discriminable, some 


\section{CORRESPONDENCES AND SYMBOLISM}

correspondences are made more or less influential (salient) by the conventions of language. In the case of English, use of the spatial height metaphor for pitch reinforces height over brightness as a feature linking with pitch. In other languages, however, the situation is different. In Farsi, for example, where a thinness-thickness metaphor is adopted for pitch, it is the interaction between thinness and pitch that induces the most noticeable congruity effect, overshadowing elevation in this regard (see Dolscheid et al., 2013). Similarly, in the author's unpublished study in which brightness and elevation were both varied simultaneously as incidental visual features, both features induced a congruity effect for participants whose first language was Norwegian. This was predicted on the grounds that a height metaphor and a brightness metaphor are both used in that language. These various observations pointing towards a degree of mutual exclusivity among congruity effects warrant further investigation because they could well be revealing a fundamental aspect of the way in which different correspondences are able to impact on behaviour.

The to-be-classified words used in the present experiments varied in their own sound features, including the auditory frequencies linked to the position of their vowels on the front/close - back/open dimension. In principle, these sound features themselves have the potential to influence the pitch classification of words, even when the words are presented visually. Participants could imagine hearing themselves, or someone else, saying the words, and the auditory frequencies in their imagery could interact with the sounds being named by the words (e.g., high pitched vowel sounds facilitating the classification of words referring to sounds also that are high pitched).

The etymology of the names of musical instruments reveals little evidence of them serving to imitate the sounds created by the instruments they name, and so it seems unlikely that their vowel sounds would support the classification decision. Unsurprisingly, however, 


\section{CORRESPONDENCES AND SYMBOLISM}

the names of sounds used in the present experiments do imitate, to some extent at least, the sounds they name (i.e., there is an element of onomatopoiea, with the vowels in the names of high pitch sounds tending to be higher in pitch than the vowels in the names of lower pitch sounds). This means that referring to the sounds of their vowels could, in principle, support the classification decision needing to be made. In the present case, however, the potential utility of doing this is undermined by the overlap, albeit modest, in the pitch of the vowel sounds across the two subsets of sound names (e.g., the vowel sound in chirp occupies the same position on the front/close - back/open dimension as the vowel sounds in groan, drone, and boom). In the event, in only one of the four experiments in which participants classified named sounds did the nature of the vowels in the names interact with the pitch of the named sounds to have a significant effect on response speed (i.e., Experiment 2b). And, as pointed out already, because variations in vowel height and vowel position were not managed with a view to properly assessing the congruity effects they might induce (rather the variations were accidental and less than optimal for this purpose), there must be some caution in accepting these significant effects as anything other than instances of a type 1 error. Crucially for the purpose of the present study, however, whatever influence the vowel sounds had on classification speeds in Experiment 2b, it did not alter the typeface congruence effect, indicating that the latter cannot be explained away as a manifestation of the former.

These secondary issues to one side, the present results provide very encouraging support for the general proposal that symbolism in language can exploit the full range of cross-sensory correspondences observed in other contexts and, as a result, can extend beyond lexical sound symbolism based on the association between auditory pitch and size. Indeed, given that stimuli in all modalities, including haptic stimuli, can engage with cross-sensory correspondences (e.g., Occelli, Spence, \& Zampini, 2009; L. Walker \& P. Walker, 2015; L. 


\section{CORRESPONDENCES AND SYMBOLISM}

Walker, P. Walker, \& Francis, 2012), symbolism based on correspondences should extend beyond the most conventional forms of spoken and written language. It should in principle, for example, be able to support symbolism when communication is via braille or signing. In signing, for example, we might expect the general position of the hands, and the sharpness of their movements, to be raised somewhat to emphasise the brightness of the concept being signed.

Returning to visual symbolism in word reading, how might the incidental visual features of a word interact with the features of the concept it names, and how might this interaction be mediated by cross-sensory correspondences? Figure 4 illustrates the problem. The orthographic encoding of a word, which is designed to isolate the abstract identities of letters from their visual features, serves to access the word's entry in the mental lexicon, and then the corresponding conceptual entries in conceptual knowledge. These conceptual entries are assumed to include representations of the known attributes of the core concept named by the word, and this will include, for example, that squeals are high pitched. The representation of high pitch as an attribute qualifies as a conceptual representation because it embraces the many different sounds able to be categorised as a squeal, with such categorisation being appropriately context sensitive (e.g., the acoustic profile of a squeal from a man will differ significantly from the profile from a young child or small animal) (see, for example, Johnson, 2015). Separate from a word's orthography, its incidental visual features (e.g., its thinness, pointiness, and brightness) also will be encoded, and the critical question then becomes: How does the encoding of these features allow them to interact with the conceptual processes underpinning the pitch classification of the sounds named by the word? 


\section{CORRESPONDENCES AND SYMBOLISM}

Figure 4. Illustrating how the elementary visual features of a word are encoded separately from its orthographic and conceptual aspects. Uncertainty about how the former might come to be able to interact with the word's conceptual attributes is flagged with a question mark.

One possibility builds on the notion that cross-sensory correspondences can be accessed through the context-sensitive categorical coding of elementary (non-verbal) stimulus features (see L. Walker \& P. Walker, 2015; P. Walker 2012; P. Walker \& L. Walker, 2012). Chiou and Rich (2012) have shown, for example, how a simple sound can be categorised as being high pitched on the basis that it is relatively high pitched compared to the other sounds being heard in the same context (rather than on the basis of its absolute acoustic frequency), and that it is on this basis that the sound engages with cross-sensory correspondences as a high pitched sound (see also Marks, 1987; Melara \& Marks, 1990). Similarly, L. Walker and P. Walker (2015) demonstrate how a circle with a particular level of visual brightness can interact with the haptic size of a response key either as a bright stimulus, or as a dark stimulus, depending on the brightness of the other circles with which it appears in the experiment. These and other demonstrations confirm the functional significance of the context sensitive categorisation of elementary stimulus features (i.e., their relative rather than absolute feature values), something that is central to Martino \& Marks', 2001, definition of cross-sensory correspondences (what, at the time, they called 'weak synaesthesia'). It seems likely, therefore, that the incidental visual features of a word also are encoded conceptually (i.e., a sample of text as a visual stimulus is categorised as being relatively thin or thick, relatively pointy or curved, and relatively bright or dark) (see L. Walker \& P. Walker, 2015; P. Walker 2012; P. Walker \& L. Walker, 2012, P. Walker, L. Walker \& Francis, 2015). 


\section{CORRESPONDENCES AND SYMBOLISM}

What remains, therefore, is to see how the conceptual representations of a word's visual features come to interact with the conceptual representations linked to the concept named by the word. One possibility has been outlined by P. Walker and his colleagues (see, for example, P. Walker, 2012; P. Walker \& L. Walker, 2012, P. Walker, L. Walker \& Francis, 2015).

Figure 5 illustrates one way in which representations of the feature dimensions involved in cross-sensory correspondences might be functionally organised. These dimensions are assumed to be conceptual in nature, and to be aligned, en bloc, in the same way regardless of the sensory channel over which elementary stimulus features are being

encoded. For example, it is the concept of something being relatively thin, or relatively thick, that is registered on the thinness-thickness dimension, not detailed modality-specific information about an instance of thinness/thickness (see Chiou \& Rich, 2014, who present a similar argument with regard to synaesthesia also). In the same way, it is the concept of something being relatively high or relatively low that is registered on the pitch dimension. Combining such functional organisation with the notion that crosstalk (mutual excitation) occurs across corresponding positions on the dimensions (P. Walker 2012; P. Walker \& L. Walker, 2012) provides a means whereby the thinness of a typeface can induce activation of the same conceptual representation of relative height (pitch) that is being activated by the name of a sound (and that can be activated by a word's vowel sound). This is made all the more likely with the finding that the same cross-sensory feature associations observed elsewhere are induced when the thinness of letter strokes is manipulated. Therefore, to the extent that the pitch classification of a named sound draws on information captured in the conceptual representations accessed by both aspects of the word (i.e., by both its meaning and its incidental visual features), then when the word's visual features are congruent with the 


\section{CORRESPONDENCES AND SYMBOLISM}

named concept everything will point to the same classification decision. When the word's visual features are incongruent with the named concept, however, then contradictory classification decisions will each find support, and additional processing will be needed to resolve the conflict (by identifying which of the contradictory classifications is linked to the meaning of the word, and which to its visual features). Resolving this conflict will delay the eventual classification of the word, compared to a congruent situation in which both aspects of the word point to the same classification decision. And of course, failing to resolve the conflict correctly will lead to incorrect classification.

(figure 5 here)

Figure 5. The functional organisation of the conceptual feature dimensions involved in cross-sensory correspondences, as proposed by P. Walker, 2012, and P. Walker \& L. Walker, 2012. With the conceptual encoding of elementary visual features allowing them to access the same conceptual dimensions as the named concept, and with crosstalk occurring between corresponding places on these dimensions, there emerges a possible means whereby cross-sensory correspondences can mediate the visual symbolism demonstrated in the present experiments.

This framework predicts a range of congruity effects qualifying as instances of visual symbolism based on cross-sensory correspondences. For example, in light of the correspondence between thinness and each of brightness, size, speed, and weight (with thin being aligned with bright, small, fast, and light in weight), presenting words in typefaces contrasting in the thinness of their letter strokes should induce congruity effects in speeded 


\section{CORRESPONDENCES AND SYMBOLISM}

decision tasks requiring people to classify words according to the brightness, size, speed, and weight of the concepts to which they refer. Likewise, with the correspondences known to involve brightness, presenting words as either white-on-grey text or as black-on-grey text should induce congruity effects in tasks requiring people to classify words according to the sharpness, size, speed, thinness, and weight of the concepts to which they refer.

The work reported here has important implications extending beyond the development of a theoretical framework by which to understand cross-sensory correspondences, and beyond demonstrating a visual equivalent of prosodic sound symbolism. Demonstrating a visual equivalent of prosodic sound symbolism, for example, opens up a line of application in sensory marketing to parallel that concerned with sound symbolism (see, for example, Klink \& Wu, 2014). For example, choosing typefaces for new brand names according to their cross-sensory features could help to establish the features desired for the brand (e.g., the sharpness of a new range of knives). Very important also, but yet to be mentioned here, are the implications of the present work for models of word reading. As Perea, Jimenez, Talero, and Lopez-Canada (2015) point out, most current models of word reading assume that the early stages in reading are designed to extract the abstract letter identities of a word as quickly as possible, so that abstract lexical units can then be accessed. In doing so, the incidental visual characteristics of a word are discarded, including details of the size, case, and font in which the word appeared. As Perea et al. themselves demonstrate, however, information about letter case is not discarded, but is taken into account during word recognition (see also Seymour \& Jack, 1978). This is consistent with Peressotti, Cubelli and Job’s (2003) account of word reading and their finding that letter case is crucially important during the reading of proper names. As P. Walker \& Hinkley (2003) point out, many words double up as a proper noun and as some other type of word, and it might only be the 


\section{CORRESPONDENCES AND SYMBOLISM}

capitalisation of the initial letter in the former that allows a statement to be correctly understood (e.g., I went to see Thomas Cook/cook, Noel is a typical Coward/coward, and She fell into the Farmers Arms/farmers arms). Like the previous study by Lewis and P. Walker (1989), the present study extends these notions to embrace the font in which a word appears as the carrier of incidential visual features that are not completely discarded during reading. Rather, according to the account offered here, the visual features characterising the font can re-engage with the processing of the word along more abstract bases, most likely at the stage where the conceptual attributes of a word's referent are represented. 


\section{References}

Algom, D., Dekel, A., \& Pansky, A. (1996). The perception of number from the separability of the stimulus: The Stroop effect revisited. Memory and Cognition, 24, 557-572.

Bates D., Maechler, M., Bolker, B. \& Walker, S. (2014). lme4: Linear mixed-effects models using Eigen and S4. R package version 1.1-7, <URL: http://CRAN.Rproject.org/package $=$ lme4 $>$.

Becker, J. A., \& Fisher, S. K. (1988). Comparison of associations to vowel speech sounds by English and Spanish speakers. American Journal of Psychology, 101, 51-57.

Bee, M. A., Perrill, S. A., \& Owen, P. C. (2000). Male green frogs lower the pitch of acoustic signals in defence of territories: A possible dishonest signal of size? Behavioral Ecology, $11,169-177$.

Bergen, B. K. (2004). The psychological reality of phonaesthemes. Language, 80, 290-311,

Berlin, B. (1994). Evidence for pervasive synesthetic sound symbolism in ethnozoological nomenclature. In L. Hinton, J. Nichols, \& J. J. Ohala (Eds), Sound Symbolism, pp. 76-93. New York: Cambridge University Press.

Besner, D. \& Coltheart, M. (1979). Ideographic and alphabetic processing in skilled reading of English. Neuropsychologia, 17, 467-472.

Childers, T. L. \& Jass, J. (2002). All dressed up with something to say: Effects of typeface semantic associations on brand perceptions and consumer memory. Journal of Consumer Psychology, 12, 93-106.

Chiou, R. \& Rich, A. N. (2014). The role of conceptual knowledge in understanding synesthesia: evaluating contemporary findings from a "hub-and-spokes" perspective. Frontiers in Psychology, 5, Article 105, 1-18. 


\section{CORRESPONDENCES AND SYMBOLISM}

Chiou, R., Stelter, M., \& Rich, A. N. (2013). Beyond colour perception: Auditory-visual synaesthesia induces experiences of geometric objects in specific locations. Cortex, 49, 1750-1763.

Collier, W. G., \& Hubbard, T. L. (2001). Judgements of happiness, brightness, speed and tempo change of auditory stimuli varying in pitch and tempo. Psychomusicology, 17, 3655.

Coulter, K. S. \& Coulter, R. A. (2005). Size does matter: The effects of magnitude representation congruency on price perceptions and purchase likelihood. Journal of Consumer Psychology, 15, 64-76.

Cutting, J. E. (2002). Representing motion in a static image: Constraints and parallels in art, science, and popular culture. Perception, 31, 1165-1193.

Davies, N. B., \& Halliday, T. R. (1978). Deep croaks and fighting assessment in toads Bufo bufo. Nature, 274, 683-685.

Dolscheid, S., Hunnius, S., Casasanto, D., \& Majid, A. (2014). Prelinguistic infants are sensitive to space-pitch associations found across cultures. Psychological Science, 25, 1256-1261.

Dolscheid, S., Shayan, S., Majid, A., \& Casasanto, D. (2013). The thickness of musical pitch: Psychophysical evidence for linguistic relativity. Psychological Science, 24, 613-621.

Doyle, J. R. \& Bottomley, P. A. (2004). Font appropriateness and brand choice. Journal of Business Research, 57, 873-880.

Doyle, J. R. \& Bottomley, P. A. (2009). The massage in the medium: Transfer of connotative meaning from typeface to names and products. Applied Cognitive Psychology, 23, 396409. 


\section{CORRESPONDENCES AND SYMBOLISM}

Eitan, Z. \& Timmers, R. (2010). Beethoven’s last piano sonata and those who follow crocodiles: Cross-domain mappings of auditory pitch in a musical context. Cognition, $114,405-422$

Evans, S., Neave, N., \& Wakelin, D. (2006). Relationships between vocal characteristics and body size and shape in human males: An evolutionary explanation for a deep male voice. Biological Psychology, 72, 160-163.

Evans, K. K. \& Treisman, A. (2010). Natural cross-modal mappings between visual and auditory features. Journal of Vision, 10(1):6, 1-12.

Fitch, W. T. (1999). Acoustic exaggeration of size in birds by tracheal elongation: Comparative and theoretical analyses, Journal of Zoology, 248, 31-49.

Fitch, W. T., \& Hauser, M. D. (2002). Unpacking 'honesty’: Vertebrate vocal production and the evolution of acoustic signals. In Acoustic Communication, edited by A.M. Simmons, R.R. Fay, and A.N. Popper. Springer: New York, pp. 65-137.

Fitousi, D. \& Algom, D. (2006). Size congruity effects with two-digit numbers: Expanding the number line? Memory and Cognition, 34, 445-457.

Foltz, G. S., Poltrock, S. E., \& Potts, G. R. (1984). Mental comparison of size and magnitude: Size congruity effects. Journal of Experimental Psychology: Learning, Memory and Cognition, 10, 442-453.

Freed, D. J. (1990). Auditory correlates of perceived mallet hardness for a set of recorded percussive sound events. Journal of the Acoustical Society of America, 87, 311-322.

Gasser, M., Sethuraman, N., \& Hockema, S. (2005). Iconicity in expressives: An empirical investigation. In Experimental and Empirical Methods in the Study of Conceptual Structure, Discourse, and Language (Rice, S. and Newman, J., eds), pp. 163-180, CSLI Publications. 
CORRESPONDENCES AND SYMBOLISM

Grassi, M. (2005). Do we hear size or sound? Balls dropped on plates. Perception \& Psychophysics, 67, 274-284.

Grassi, M., Pastore, M., \& Lemaitre, G. (2013). Looking at the world with your ears: How do we get the size of an object from its sound? Acta Psychologica, 143, 96-104.

Hatta, T. (1983). Recognition of Japanese Kanji in the left and right visual field. Neuropsychologia, 21, 669-678.

Harrington, F. H. (1987). Aggressive howling in wolves. Animal Behavior, 35, 7-12.

Haryu, E. \& Kajikawa, S. (2012). Are higher-frequency sounds brighter in color and smaller in size? Auditory-visual correspondences in 10-month-old infants. Infant Behavior and Development, 35, 727-732.

Henik, A. \& Tzelgov, J. (1982). Is three greater than five: The relation between physical and semantic size in comparison tasks. Memory and Cognition, 10, 389-395.

Houben, M. M. J., Kohlrausch, A., \& Hermes, D. J. (2004). Perception of the size and speed of rolling balls by sound. Speech Communication, 43, 331-345.

Hubbard, T. L. (1996). Synesthesia-like mappings of lightness, pitch, and melodic interval. American Journal of Psychology, 109, 219-238.

Iwaraha, A., Hatta, T., \& Maehara. A. (2003). The effects of a sense of compatibility between type of script and word in written Japanese. Reading and Writing, 16, 377-397.

Johnson, K. (2005). Speaker normalization in speech perception. In D. B. Pisoni \& R. Remez (eds), The Handbook of Speech Perception. Oxford: Blackwell Publishers. pp. 363-389.

Johnson, R. C. (1967). Magnitude symbolism of English words. Journal of Verbal Learning and Verbal Behavior, 6, 508-511.

Jones, M., Vinson, D., Clostre, N., Zhu, A. L., Santiago, J., \& Vigliocco, G. (2014). The bouba effect: Sound-shape iconicity in iterated and implicit learning. Proceedings of the 


\section{CORRESPONDENCES AND SYMBOLISM}

$36^{\text {th }}$ Annual Meeting of the Cognitive Science Society. Quebec City. https://mindmodeling.org/cogsci2014/papers/427/paper427.pdf

Karwoski, T. F. \& Odbert, H. S. (1938). Color-music. Psychological Monographs, 50(2), 160.

Karwoski, T. F., Odbert, H. S., \& Osgood, C. E. (1942). Studies in synesthetic thinking: II. The role of form in visual responses to music. The Journal of General Psychology, 26, 199-222.

Kelly, M. H., Springer, K., \& Keil, F. C. (1990). The relation between syllable number and visual complexity in the acquisition of word meanings. Memory and Cognition, 18, 528536.

Klatzky, R. L., Pai, D. K., \& Krotkov, E. P. (2000). Perception of material from contact sounds. Presence, 9, 399-410.

Klink, R. R. (2000). Creating brand names with meaning: The use of sound symbolism. Marketing Letters, 11, 5-20.

Klink, R. R. (2003). Creating meaningful brands: The relationship between brand name and brand mark. Marketing Letters, 14, 143-157.

Klink, R. R. \& Wu, L. (2014). The role of position, type, and combination of sound symbolism imbeds in brand names. Marketing Letters, 25, 13-24.

Köhler, W (1947). Gestalt Psychology, 2nd Ed. New York: Liveright.

Koriat, A. \& Levy, I. (1979). Figural symbolism in Chinese ideographs. Journal of Psycholinguistic Research, 8, 353-365.

Kunihira, S. (1971). Effects of the expressive voice on phonetic symbolism. Journal of Verbal Learning and Verbal Behavior, 10, 427-429. 


\section{CORRESPONDENCES AND SYMBOLISM}

Kussner, M. B. \& Leech-Wilkinson, D. (2013). Investigating the influence of musical training on cross-modal correspondences and sensorimotor skills in a real-time drawing task. Psychology of Music, 42, 448-469.

Lewis, C. \& Walker, P. (1989). Typographic influences on reading. British Journal of Psychology, 80, 241-257.

Lowry, T. M. \& Shrum, L. J. (2007). Phonetic symbolism and brand name preference. Journal of Consumer Research, 34, 406-414.

Lundholm, H. (1921). The affective tone of lines: Experimental researches. Psychological Review, 28, 43-60.

Marks, L. E. (1974). On associations of light and sound: The mediation of brightness, pitch, and loudness. American Journal of Psychology, 87, 173-188.

Marks, L. E. (1975). On colored-hearing synaesthesia: Cross-modal translations of sensory dimensions. Psychological Bulletin, 82, 303-331.

Marks, L. E. (1978). The unity of the senses: Interrelations among the modalities. New York: Academic Press.

Marks, L. E. (1987). On cross-modal similarity: Auditory-visual interactions in speeded discrimination. Journal of Experimental Psychology: Human Perception \& Performance, 13, 384-394.

Martino, G., \& Marks, L. E. (2001). Synaesthesia: Strong and weak. Current Directions in Psychological Science, 10, 61-65.

McMurray, G. A. (1958). A study of “fittingness” of signs to words by means of the semantic differential. Journal of Experimental Psychology, 56, 310-312.

McMurray, G. A. (1960). Meaning associated with the phonetic structure of unfamiliar foreign words. Canadian Journal of Psychology, 14, 166-174. 


\section{CORRESPONDENCES AND SYMBOLISM}

Melara, R. D. \& Marks, L. E. (1990). Processes underlying dimensional interactions: Correspondences between linguistic and nonlinguistic dimensions. Memory \& Cognition, 18, 477-495.

Monaghan, P., Mattock, K., \& Walker, P. (2012). The role of sound symbolism in word learning. Journal of Experimental Psychology: Learning, Memory, \& Cognition, 38, 1152-1164.

Monaghan, P., Shillcock, R. C., Christiansen, M. H., \& Kirby, S. (2014). How arbitrary is language? Philosophical Transactions of the Royal Society B, 369, p. 20130299

Mondloch, C. J. \& Maurer, D. (2004). Do small white balls squeak? Pitch-object correspondences in young children. Cognitive, Affective, and Behavioral Neuroscience, 4, 133-136.

Morton, E. S. (1994). Sound symbolism and its role in non-human vertebrate communication. In L. Hinton, J. Nichols, \& J. J. Ohala (Eds), Sound Symbolism, pp. 348-365. New York: Cambridge University Press.

Newman, S. S. (1933). Further experiments in phonetic symbolism. American Journal of Psychology, 45, 53-75.

Nielsen, A. \& Rendall, D. (2011). The sound of round: Evaluating the sound-symbolic role of consonants in the classic Takete-Maluma phenomenon. Canadian Journal of Experimental Psychology, 65, 115-124.

Nygaard, L.C., Herold, D.S. \& Namy, L.L. (2009). The semantics of prosody: Acoustic and perceptual evidence of prosodic correlates to word meaning. Cognitive Science, 33, 127146.

Occelli, V., Spence, C., \& Zampini, M. (2009). Compatibility effects between sound frequency and tactile elevation. NeuroReport, 20, 793-797. 


\section{CORRESPONDENCES AND SYMBOLISM}

Ohala, J. J. (1994). The frequency code underlies the sound-symbolic use of voice pitch. In L. Hinton, J. Nichols, \& J. J. Ohala (Eds), Sound Symbolism, pp. 325-347. New York: Cambridge University Press.

Osgood, C. E. (1960). The cross-cultural generality of visual-verbal synesthetic tendencies. Behavioral Sciences, 5, 146-169.

Ozturk, O., Krehm, M., \& Vouloumanos, A. (2013). Sound symbolism in infancy: Evidence for sound-shape cross-modal correspondences in 4-month-olds. Journal of Experimental Child Psychology, 114, 173-186.

Pan, Y. \& Schmitt, B. (1996). Language and brand attitudes: Impact of script and sound matching in Chinese and English. Journal of Consumer Psychology, 5, 263-277.

Parise, C. V. \& Pavani, F. (2011). Evidence of sound symbolism in simple vocalizations. Experimental Brain Research, 214, 373-380.

Pena, M., Mehler, J. \& Nespor, M. (2011). The role of audiovisual processing in early conceptual development. Psychological Science, 22, 1419-1421.

Perea, M., Jimenez, M., Talero, F., \& Lopez-Canada, S. (2015). Letter-case information and the identification of brand names. British Journal of Psychology, 106, 162-173.

Peressotti, F., Cubelli, R., \& Job, R. (2003). On recognizing proper names: The orthographic cue hypothesis. Cognitive Psychology, 47, 87-116.

Perniss P, Thompson RL, Vigliocco G. 2010 Iconicity as a general property of language: evidence from spoken and signed languages. Frontiers in Psychology, 1, 227. doi:10.3389/fpsyg.2010.00227

Perrott, D. R., Musicant, A., \& Schwethelm, B. (1980). The expanding image effect: The concept of tonal volume revisited. Journal of Auditory Research, 20, 43-55.

Pisanski, K., Fraccaro, P. J., Tigue, C. C., O’Connor, J. J. M., Roder, S., Andrews, P. W., 


\section{CORRESPONDENCES AND SYMBOLISM}

Fink, B., DeBruine, L. M., Jones, B. C., \& Feinberg, D. R. (2014). Vocal indicators of body size in men and women: A meta-analysis. Animal Behaviour, 95, 89-99.

Pisanski, K. \& Rendall, D. (2011). The prioritization of voice fundamental frequency or formants in listeners’ assessments of speaker size, masculinity, and attractiveness. Journal of the Acoustical Society of America, 129, 2201-2212.

Poffenberger, A. T. \& Barrows, B. E. (1924). The feeling value of lines. Journal of Applied Psychology, 8, 187-205.

R Core Team (2012). R: A language and environment for statistical computing. $R$ Foundation for Statistical Computing. Vienna: Austria.

Reich, S. S. \& Cherry, C. (1979). A direct access from graphics to meaning: A study of the Stroop effect in sentences. In P. A. Kolers, M. E. Wrolstad, \& H. Bouma (Eds), Processing of Visible Language, volume 1, pp. 371-377. New York: Plenum.

Rendell, D. Vokey, J. R., \& Nemeth, C. (2007). Lifting the curtain on the Wizard of Oz: Biassed voice-based impressions of speaker size. Journal of Experimental Psychology: Human Perception and Performance, 33, 1208-1219.

Rhodes, R. (1994). Aural images. In L. Hinton, J. Nichols, \& J. J. Ohala (Eds), Sound Symbolism, pp. 276-292. New York: Cambridge University Press.

Rubinsten, O. \& Henik, A. (2002). Is an ant larger than a lion? Acta Psychologica, 111, 141154.

Sapir, E. (1929). A study of phonetic symbolism. Journal of Experimental Psychology, 12, 225-239.

Scheerer, M. \& Lyons, J. (1957). Line drawings and matching responses to words. Journal of Personality, 25, 251-273. 


\section{CORRESPONDENCES AND SYMBOLISM}

Seymour, P. H. \& Jack, M. V. (1978). Effects of visual familiarity on "same” and "different” decision processes. Quarterly Journal of Experimental Psychology, 30, 455-469.

Sicoli, M. A. (2010). Shifting voices with participant roles: Voice qualities and speech registers in Mesoamerica. Language in Society, 39, 521-553.

Spector, F. \& Maurer, D. (2013). Early sound symbolism for vowel sounds. i-Perception, 4, 239-241.

Tarte, R. D. (1982). The relationship between monosyllables and pure tones: An investigation of phonetic symbolism. Journal of Verbal Learning and Verbal Behavior, 21, 352-360.

Tzelgov, J., Meyer, J., \& Henik, A. (1992). Automatic and intentional processing of numerical information. Journal of Experimental Psychology: Learning, Memory, and Cognition, 18, 166-179.

Vaid, J. (1985). Numerical size comparisons in a phonologically transparent script. Perception and Psychophysics, 37, 592-595.

van den Doel, K., \& Pai, D. K. (1998). The sounds of physical shapes. Presence, 7, 382-395.

Van Leeuwen, T. (2006). Towards a semiotics of typography. Information Design Journal, $14,139-155$.

Walker, L. \& Walker, P. (2015). Cross-sensory mapping of feature values in the sizebrightness correspondence can be more relative than absolute. Journal of Experimental Psychology: Human Perception and Performance, in press.

Walker, L., Walker, P., \& Francis, B. J. (2012). A common scheme for cross-sensory correspondences across stimulus domains. Perception, 41(10), 1186-1192.

Walker, P. \& Hinkley, L. (2003). Visual memory for shape-colour conjunctions utilizes structural descriptions of letter shape. Visual Cognition, 10, 987-1000.

Walker, P. (2008). Font tuning: A review and new experimental evidence. Visual Cognition, 


\section{CORRESPONDENCES AND SYMBOLISM}

16, 1022-1058.

Walker, P. (2012). Cross-sensory correspondences and crosstalk between dimensions of connotative meaning: Visual angularity is hard, high-pitched, and bright. Attention, Perception, \& Psychophysics, 74, 1792-1809.

Walker, P. (2015). Depicting visual motion in still images: Forward leaning and a left to right bias for lateral movement. Perception, 44, 111-128.

Walker, P., Bremner, J. G., Mason, U., Spring, J., Mattock, K., Slater, A., \& Johnson, S. (2010). Preverbal infants' sensitivity to synaesthetic cross-modality correspondences. Psychological Science, 21(1), 21-25.

Walker, P. \& Smith, S. (1984). Stroop interference based on the synaesthetic qualities of auditory pitch. Perception, 13, 75-81.

Walker, P., Smith, S., \& Livingston, A. (1986). Predicting the appropriateness of a typeface on the basis of its supramodal features. Information Design Journal, 5, 29-42.

Walker, P. \& Walker, L. (2012). Size-brightness correspondence: Crosstalk and congruity among dimensions of connotative meaning. Attention, Perception, \& Psychophysics, 74, 1226-1240.

Walker, P., Walker, L. \& Francis, B. J. (2015). The size-brightness correspondence: Evidence for crosstalk among aligned conceptual feature dimensions. Attention, Perception and Psychophysics, in press

Ward, J., Huckstep, B., \& Tsakanikos, E. (2006). Sound-colour synaesthesia: To what extent does it use cross-modal mechanisms common to us all? Cortex, 42, 264-280.

Westbury, C. (2005). Implicit sound symbolism in lexical access: Evidence from an interference task. Brain and Language, 93, 10-19. 
CORRESPONDENCES AND SYMBOLISM 


\section{Appendix}

\begin{tabular}{|c|c|c|c|c|}
\hline & $\begin{array}{l}\text { single sample } \\
t \text { value }\end{array}$ & $\begin{array}{l}\text { single sample } \\
t \text { value }{ }^{\S}\end{array}$ & $\begin{array}{l}\text { mean difference } \\
\text { in rating }\end{array}$ & $\begin{array}{l}\text { paired } \\
t \text { value }\end{array}$ \\
\hline \multicolumn{5}{|c|}{ feature dimension } \\
\hline & Palatino Italic & Cooper Black & \multicolumn{2}{|c|}{ Palatino Italic - Cooper Black } \\
\hline thick-thin & $9.91 * * *$ & $23.43 * * *$ & 4.95 & $17.52 * * *$ \\
\hline heavy-light & $6.81 * * *$ & $8.98 * * *$ & 4.05 & $10.32 * * *$ \\
\hline low-high pitch & $4.97 * * *$ & $3.74 * * *$ & 2.82 & $6.08 * * *$ \\
\hline blunt-sharp & $4.33 * * *$ & $4.47 * * *$ & 2.68 & $7.16 * * *$ \\
\hline big-small & $2.43 *$ & $9.41 * * *$ & 2.27 & $7.33 * * *$ \\
\hline slow-fast & $3.53 * *$ & $2.81 *$ & 2.18 & $3.81 * * *$ \\
\hline \multirow[t]{2}{*}{ dull-bright } & $3.35 * *$ & $1.70 \mathrm{~ns}$ & 1.68 & $2.77 *$ \\
\hline & Swiss Light & Swiss Black & \multicolumn{2}{|c|}{ Swiss Black - Swiss Light } \\
\hline thick-thin & $10.73 * * *$ & $13.94 * * *$ & 4.14 & $15.57 * * *$ \\
\hline heavy-light & $3.92 * * *$ & $6.67 * * *$ & 3.00 & $6.87 * * *$ \\
\hline low-high pitch & $1.90 \mathrm{~ns}$ & $5.53 * * *$ & 2.09 & $5.23 * * *$ \\
\hline blunt-sharp & $1.31 \mathrm{~ns}$ & $2.21 *$ & 1.27 & $2.31 *$ \\
\hline big-small & $-0.32 \mathrm{~ns}$ & $2.53 *$ & 0.91 & 1.87 \\
\hline slow-fast & $2.64 *$ & $4.11 * * *$ & 1.95 & $5.06 * * *$ \\
\hline \multirow[t]{2}{*}{ dull-bright } & $2.78 *$ & $3.55 * *$ & 2.05 & $4.25 * * *$ \\
\hline & Perpetua & Chalkboard & \multicolumn{2}{|c|}{ Chalkboard - Perpetua } \\
\hline thick-thin & $0.57 \mathrm{~ns}$ & $6.62 * * *$ & 2.00 & $6.48 * * *$ \\
\hline heavy-light & $1.06 \mathrm{~ns}$ & $7.93 * * *$ & 1.95 & $5.89 * * *$ \\
\hline low-high pitch & $1.00 \mathrm{~ns}$ & $2.32 *$ & 1.05 & $2.38 *$ \\
\hline blunt-sharp & $3.50 * *$ & $4.83 * * *$ & 2.45 & $5.24 * * *$ \\
\hline big-small & $-0.62 \mathrm{~ns}$ & $0.57 \mathrm{~ns}$ & 0 & 0 \\
\hline slow-fast & $0.50 \mathrm{~ns}$ & $4.67 * * *$ & 1.36 & $3.81 * * *$ \\
\hline \multirow[t]{2}{*}{ dull-bright } & $1.68 \mathrm{~ns}$ & $1.95 \mathrm{~ns}$ & 1.05 & $2.98 * *$ \\
\hline & Swiss Light Italic & Swiss Light & \multicolumn{2}{|c|}{ Swiss Light - Swiss Light Italic } \\
\hline thick-thin & $13.94 * * *$ & $10.73 * * *$ & 0.50 & $2.73 *$ \\
\hline heavy-light & $5.43 * * *$ & $3.92 * * *$ & 0.45 & $1.34 \mathrm{~ns}$ \\
\hline low-high pitch & $5.41 * * *$ & $1.90 \mathrm{~ns}$ & 1.09 & $3.03 * *$ \\
\hline blunt-sharp & $2.02 \mathrm{~ns}$ & $1.31 \mathrm{~ns}$ & 0.45 & $1.10 \mathrm{~ns}$ \\
\hline big-small & $0.92 \mathrm{~ns}$ & $-0.32 \mathrm{~ns}$ & 0.36 & $1.14 \mathrm{~ns}$ \\
\hline slow-fast & $4.91 * * *$ & $2.64 *$ & 1.14 & $2.54 *$ \\
\hline dull-bright & $5.04 * * *$ & $2.78 *$ & 0.68 & $1.95 \mathrm{~ns}$ \\
\hline
\end{tabular}

Note. ${ }^{* * *} p=<.001,{ }^{* * *} p=<.01,{ }^{* * *} p=<.05$, and $\S=4.0$ as the reference value for single sample $t$-test 
CORRESPONDENCES AND SYMBOLISM

\section{Palatino Italic Cooper Black}

Figure 1. 

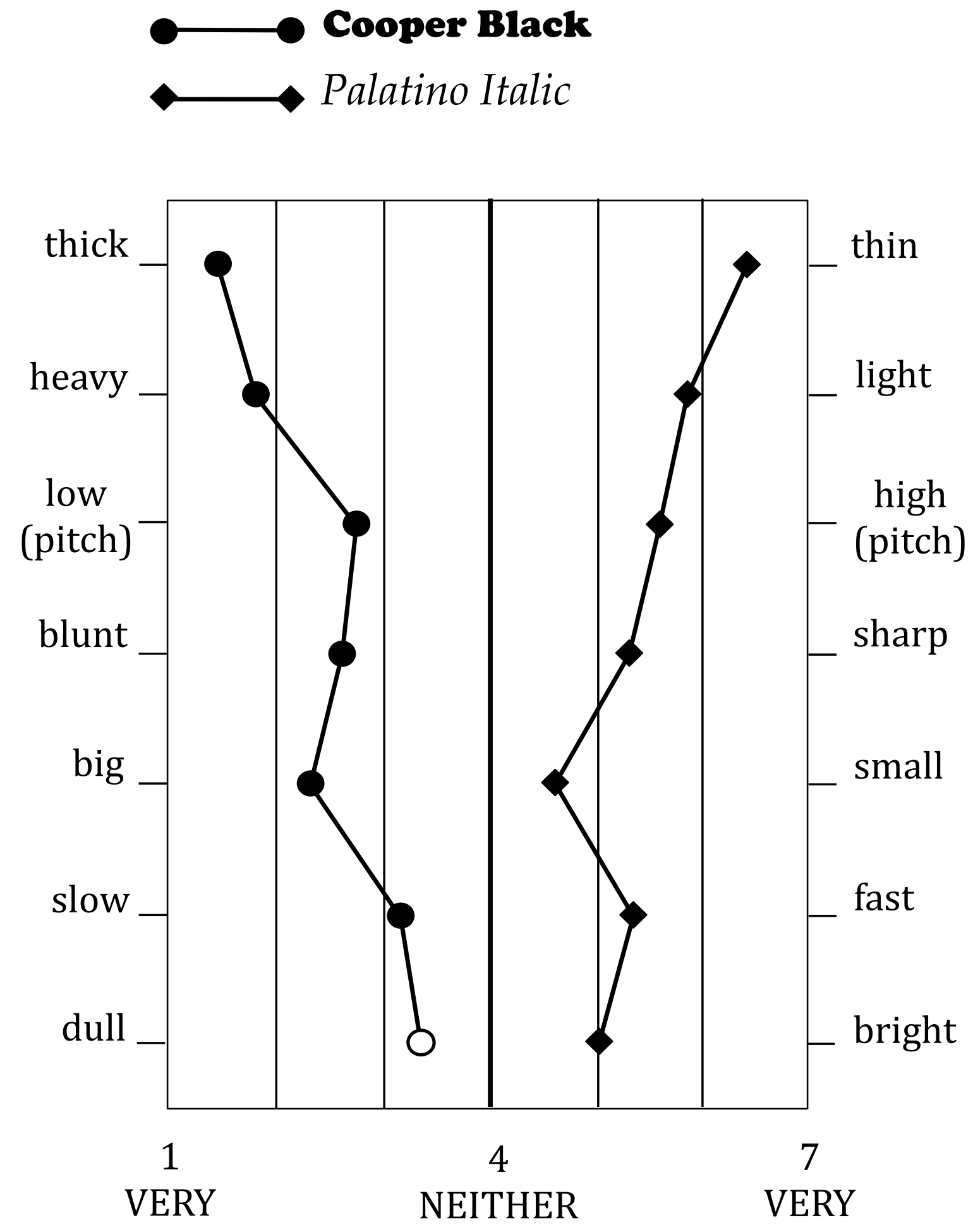

(Figure 2A) 


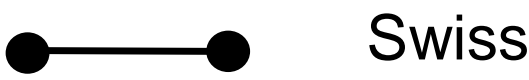

$\longrightarrow$ Swiss Light

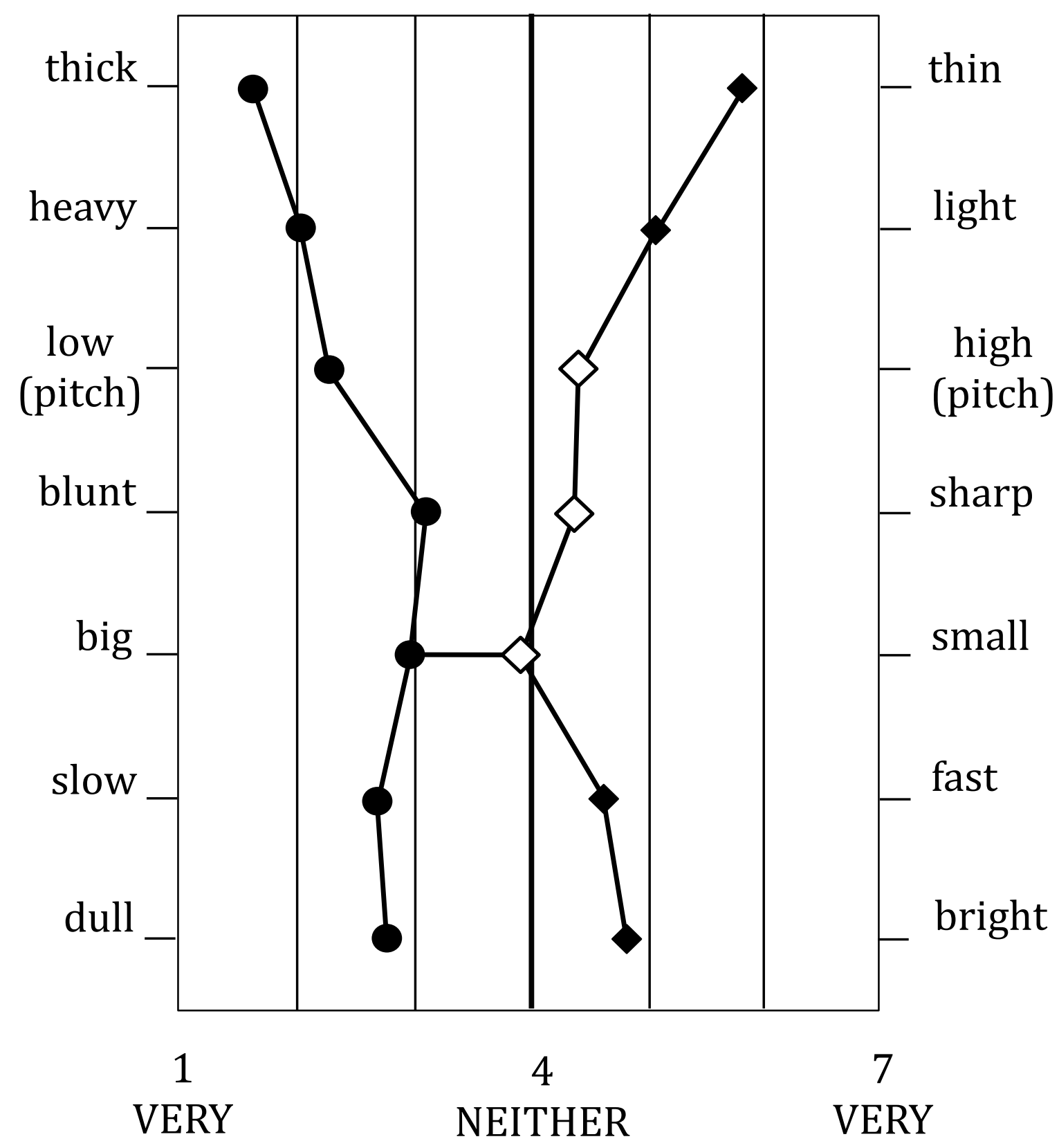

(Figure 2B) 

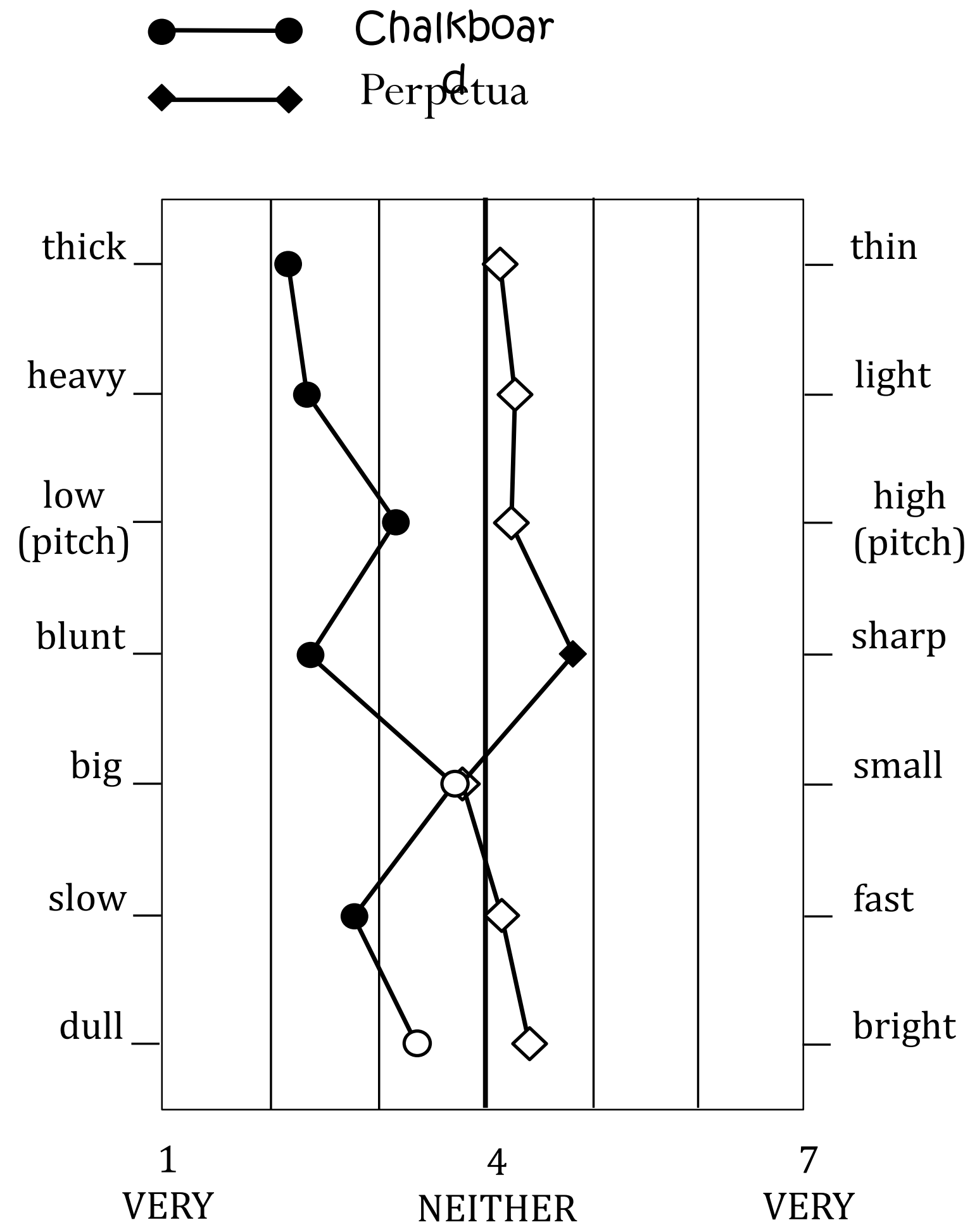

(Figure 2C) 
$\longrightarrow$ Swiss Light

Swiss Light Italic

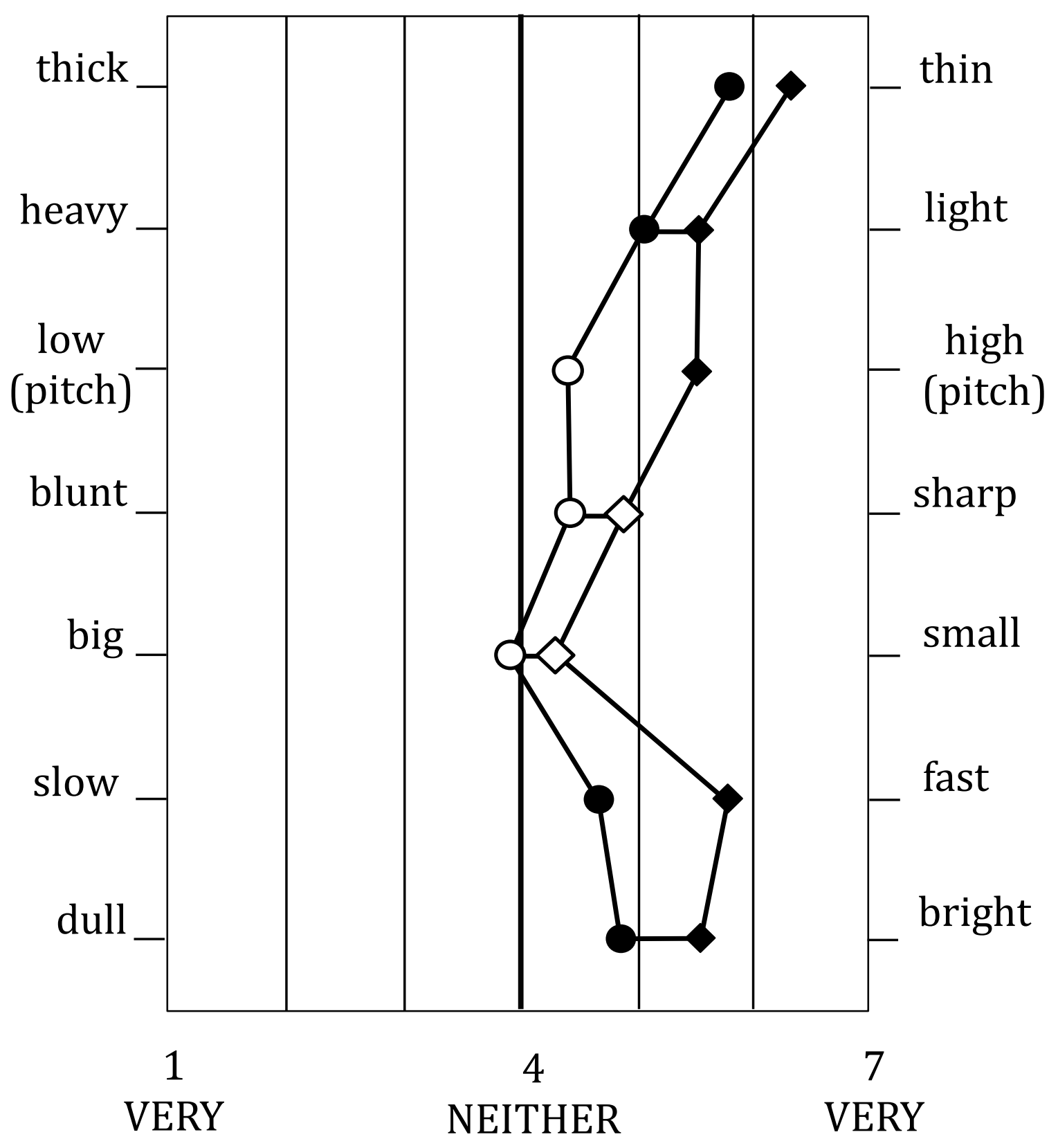

(Figure 2D) 


\section{CORRESPONDENCES AND SYMBOLISM}

Table 2. Mean values for vowel (tongue) position and vowel (tongue) height for each of the test words used in the speeded pitch classification task.

Values for individual vowel position range from 1 (front) to 3 (back), and values for individual vowel height range from 1 (close) to 4 (open). Also listed are the mean ratings for the characteristic loudness of the named sounds as determined using a 9-point scale running from 1 (quiet) to 9 (loud)

vowel position vowel height loudness

musical instruments

$\begin{array}{llll}\text { flute } & 3.0 & 1.0 & 3.6 \\ \text { piccolo } & 1.9 & 2.0 & 3.6 \\ \text { trumpet } & 2.2 & 2.2 & 6.9 \\ \text { violin } & 1.6 & 2.2 & 4.9 \\ \text { bassoon } & 2.5 & 1.7 & 6.4 \\ \text { doublebass } & 2.1 & 2.4 & 6.5 \\ \text { timpani } & 1.7 & 1.8 & 5.4 \\ \text { tuba } & 2.5 & 1.7 & 7.2\end{array}$

sounds

$\begin{array}{llll}\text { chirp } & 2.0 & 2.5 & 3.4 \\ \text { ping } & 1.5 & 1.5 & 4.3 \\ \text { shriek } & 1.0 & 1.0 & 7.2 \\ \text { squeal } & 1.0 & 1.0 & 5.7 \\ \text { boom } & 3.0 & 1.0 & 7.8 \\ \text { drone } & 2.2 & 2.0 & 4.1 \\ \text { groan } & 2.2 & 2.0 & 4.3 \\ \text { thud } & 3.0 & 3.0 & 6.7\end{array}$


Table 3. Experiments 1a and 1b: Mean correct RTs (ms)

(SEs in parentheses), derived from mean response speeds, and Error Rates (\%) according to whether test words appeared in a congruent or an incongruent typeface

\begin{tabular}{ll}
\hline & $\%$ Error
\end{tabular}

Typeface Congruency

Experiment 1a: Musical instruments

$\begin{array}{lcc}\text { Incongruent } & 709(9) & 5.0 \\ \text { Congruent } & 675(9) & 2.2 \\ \text { Incong-Cong } & 34 & 2.8\end{array}$

Experiment 1b: Names of sounds

$\begin{array}{lcc}\text { Incongruent } & 685(6) & 2.5 \\ \text { Congruent } & 649(6) & 0.7 \\ \text { Incong-Cong } & 36 & 1.8\end{array}$



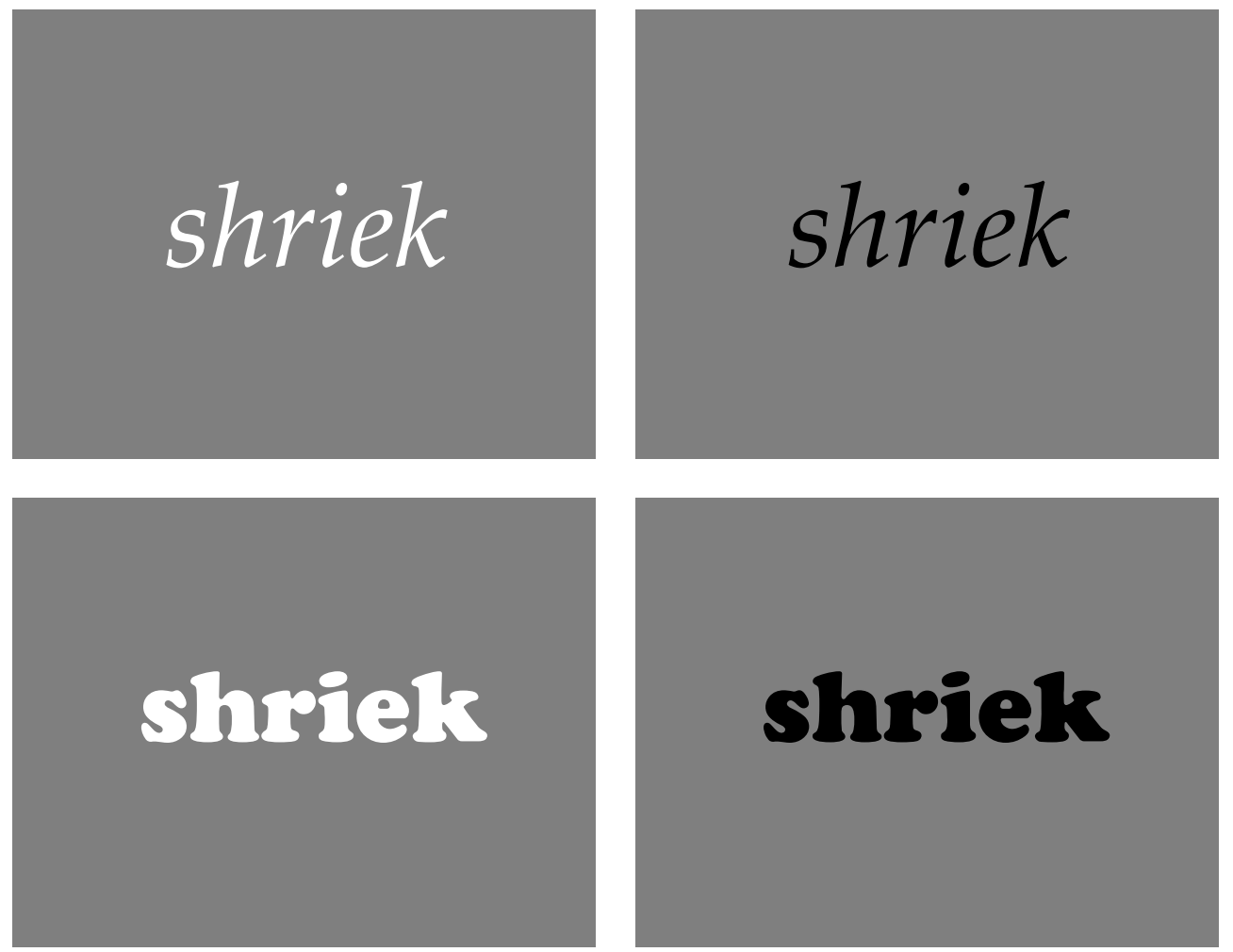

Figure 3. 


\section{CORRESPONDENCES AND SYMBOLISM}

Table 4. Experiment 2a and 2b: Mean correct RTs (ms) (SEs in parentheses), derived from mean response speeds, and Error Rates (\%) according to whether test words appeared in a congruent or incongruent typeface, or with a congruent or incongruent level of brightness

Experiment 2a: Musical instruments

Typeface Congruency

$\begin{array}{lcc}\text { Incongruent } & 610(6) & 2.5 \\ \text { Congruent } & 588(6) & 2.2 \\ \text { Incong-Cong } & 22 & 0.3\end{array}$

Brightness Congruency

$\begin{array}{lcc}\text { Incongruent } & 602(6) & 2.7 \\ \text { Congruent } & 595(6) & 2.0 \\ \text { Incong-Cong } & 7 & 0.7\end{array}$

Experiment 2b: Names of sounds

Typeface Congruency

$\begin{array}{lcc}\text { Incongruent } & 550(5) & 2.4 \\ \text { Congruent } & 535(5) & 1.9 \\ \text { Incong-Cong } & 15 & 0.5\end{array}$

Brightness Congruency

$\begin{array}{lcc}\text { Incongruent } & 543(5) & 3.0 \\ \text { Congruent } & 540(5) & 1.3 \\ \quad \text { Incong-Cong } & 3 & 1.7\end{array}$


Table 5. Experiment 3: Mean correct RTs (ms) (SEs in parentheses), derived from mean response speeds, and Error Rates (\%) according to whether test words appeared in a congruent or an incongruent typeface, or with a congruent or incongruent level of brightness

$M$

$\%$ Error

Experiment 3: Names of sounds

Typeface Congruency

$\begin{array}{lcc}\text { Incongruent } & 602(7) & 3.1 \\ \text { Congruent } & 595(7) & 2.3 \\ \quad \text { Incong-Cong } & 7 & 0.8\end{array}$

Brightness Congruency

$\begin{array}{lcc}\text { Incongruent } & 613(7) & 3.6 \\ \text { Congruent } & 584(7) & 1.8 \\ \text { Incong-Cong } & 29 & 1.8\end{array}$




\section{CORRESPONDENCES AND SYMBOLISM}

Table 6. Experiment 4: Mean correct RTs (ms) (SEs in paretheses), derived from mean response speeds, and Error Rates (\%) according to whether sound names appeared in a congruent or incongruent typeface, or with a congruent or incongruent level of brightness

$M$

$\%$ Error

Experiment 4: Names of sounds

Typeface Congruency

$\begin{array}{lcc}\text { Incongruent } & 568(7) & 3.3 \\ \text { Congruent } & 549(7) & 2.5 \\ \text { Incong-Cong } & 19 & 0.8\end{array}$

Brightness Congruency

$\begin{array}{lcc}\text { Incongruent } & 562(7) & 2.8 \\ \text { Congruent } & 556(7) & 3.0 \\ \text { Incong-Cong } & 6 & 0.2\end{array}$




\section{CONCEPTUAL KNOWLEDGE}

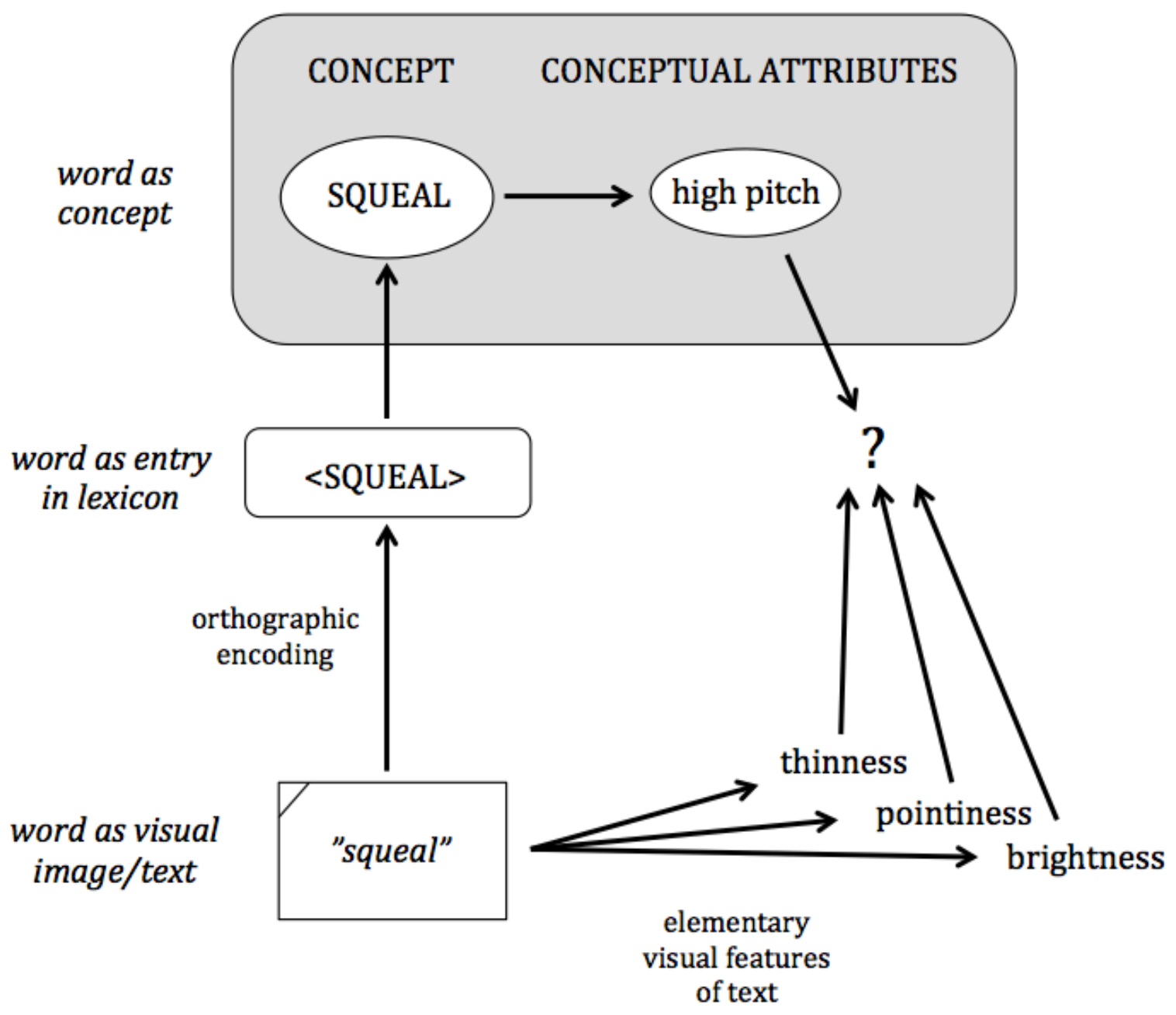

Figure 4. 


\section{CONCEPTUAL KNOWLEDGE}

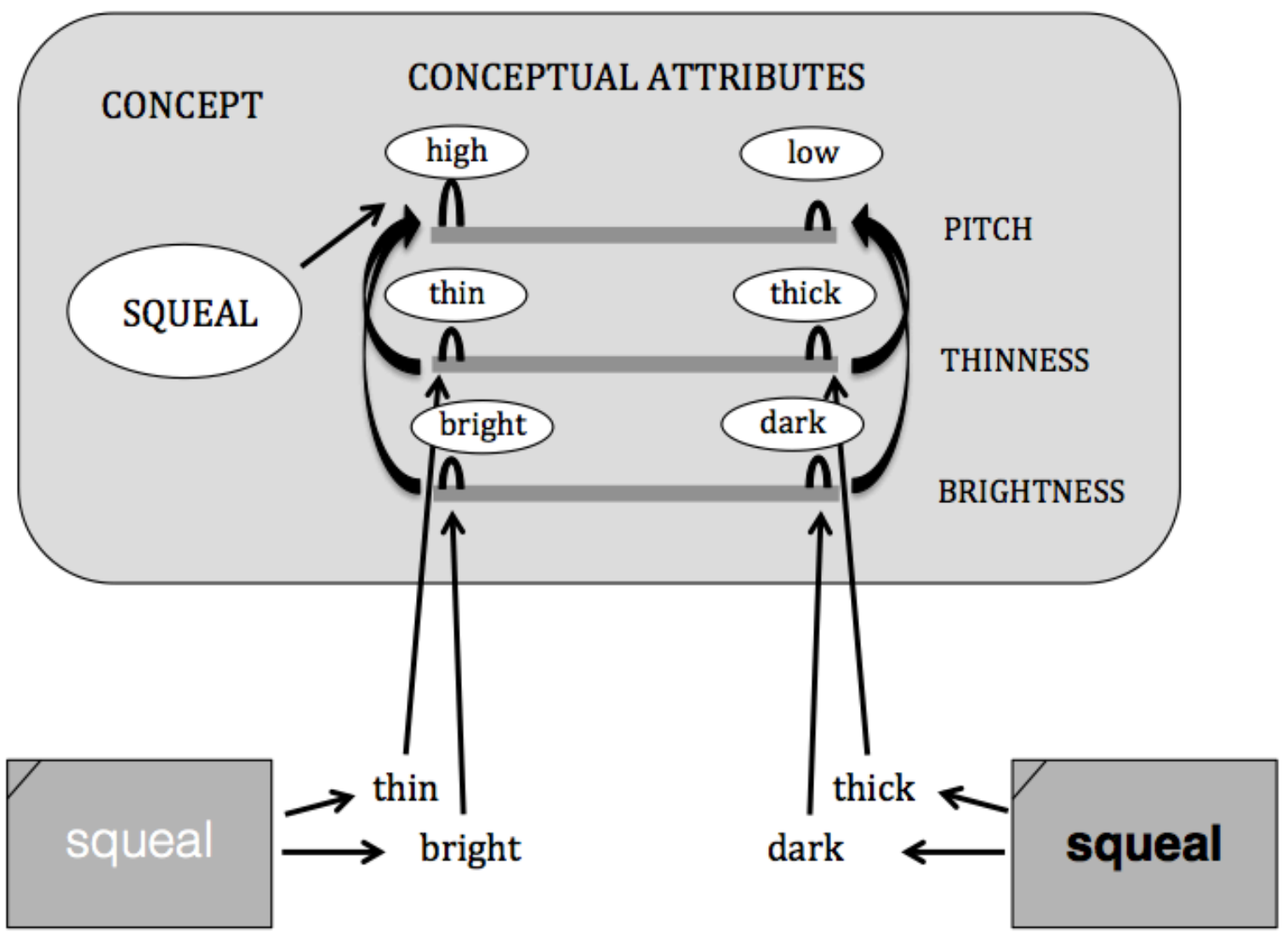

elementary visual

features of text

Figure 5. 